\title{
Molecular Mapping of Brain Areas Involved in Parrot Vocal Communication
}

\author{
ERICH D. JARVIS ${ }^{1 *}$ AND CLAUDIO V. MELLO ${ }^{2}$ \\ ${ }^{1}$ Department of Neurobiology, Duke University Medical Center, \\ Durham, North Carolina 27710 \\ ${ }^{2}$ Laboratory of Animal Behavior, The Rockefeller University, New York, New York 10021
}

\begin{abstract}
Auditory and vocal regulation of gene expression occurs in separate discrete regions of the songbird brain. Here we demonstrate that regulated gene expression also occurs during vocal communication in a parrot, belonging to an order whose ability to learn vocalizations is thought to have evolved independently of songbirds. Adult male budgerigars (Melopsittacus undulatus) were stimulated to vocalize with playbacks of conspecific vocalizations (warbles), and their brains were analyzed for expression of the transcriptional regulator ZENK. The results showed that there was distinct separation of brain areas that had hearing- or vocalizing-induced ZENK expression. Hearing warbles resulted in ZENK induction in large parts of the caudal medial forebrain and in 1 midbrain region, with a pattern highly reminiscent of that observed in songbirds. Vocalizing resulted in ZENK induction in nine brain structures, seven restricted to the lateral and anterior telencephalon, one in the thalamus, and one in the midbrain, with a pattern partially reminiscent of that observed in songbirds. Five of the telencephalic structures had been previously described as part of the budgerigar vocal control pathway. However, functional boundaries defined by the gene expression patterns for some of these structures were much larger and different in shape than previously reported anatomical boundaries. Our results provide the first functional demonstration of brain areas involved in vocalizing and auditory processing of conspecific sounds in budgerigars. They also indicate that, whether or not vocal learning evolved independently, some of the gene regulatory mechanisms that accompany learned vocal communication are similar in songbirds and parrots. J. Comp. Neurol. 419:1-31, 2000. ๑ 2000 Wiley-Liss, Inc.
\end{abstract}

Indexing terms: immediate early genes; evolution; neuroethology; parakeet; song system; avian species

Other than in humans, cetaceans, and bats, vocal learning has been found to occur in three orders of birds: oscine passeriformes (songbirds), psittaciformes (parrots), and trochiloformes (hummingbirds; cetaceans: Caldwell and Caldwell, 1972; Guinee and Payne, 1988; Reiss and McCowan, 1993; bats: Esser, 1994; birds: Thorpe, 1961; Marler, 1970, 1977; Wiley, 1971; Nottebohm, 1972, 1980; Kroodsma, 1982; Dooling et al., 1987; Baptista and Schuchmann, 1990; Brenowitz, 1991, 1997; Kroodsma and Konishi, 1991; Gaunt et al., 1994). Figure 1 shows an avian family tree, indicating the relationship of the three vocal learning bird orders to other groups, based on DNA hybridization (Sibley and Ahlquist, 1990). The neurobiology of vocal communication has been most extensively studied in oscines, where a set of discrete forebrain nuclei involved in song learning and production were first mapped (Nottebohm et al., 1976, 1982; Bottjer et al., 1989;
Johnson et al., 1995; Vates et al., 1997; Foster et al., 1997). These nuclei, collectively known as the 'song system', project to motor neurons that innervate the trachea and syrinx and control their function in coordination with respiratory movements (reviewed by Wild, 1994, 1997). Although very little information is available on hummingbirds, forebrain nuclei projecting directly or indirectly to motor neurons that innervate the vocal organs have also been described in a parrot, the budgerigar. Some of these nuclei occur in anatomical locations similar to those of the

*Correspondence to: Erich D. Jarvis, Assistant Professor, Department of Neurobiology, Box 3209, Duke University Medical Center, Durham, NC 27710. E-mail: jarvis@neuro.duke.edu

Received 28 January 1999; Revised 14 July 1999; Accepted 3 August 1999 


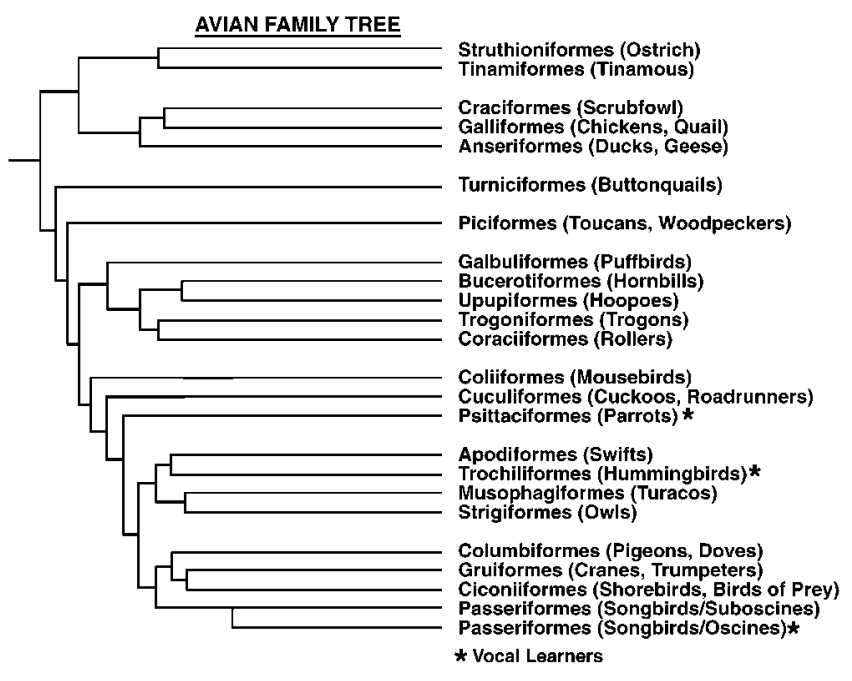

Fig. 1. Avian family tree of modern bird orders reconstructed from that of Sibley and Ahlquist (1990, p 838). Branching points are based on bootstrap values calculated from DNA-DNA hybridization melting temperatures (Sibley and Ahlquist, 1990). Actual values are not shown. We separated oscines from suboscines and included one or two common species names for birds of each order.

song control nuclei found in songbirds (Paton et al., 1981; Striedter, 1994; Durand et al., 1997). Because forebrain vocal nuclei and vocal learning have not been found in suboscines, the closest relative of oscine songbirds (Nottebohm, 1980; Kroodsma and Konishi, 1991; Fig. 1), nor in interrelated groups, such as columbiformes (doves and pigeons; Konishi and Nottebohm, 1969; Nottebohm and Nottebohm, 1971; Wild et al., 1990, 1997b), or distantly related ones, such as galliformes (chicken and fowl; Konishi and Nottebohm, 1969; Bonke et al., 1979), it has been proposed that vocal learning and associated neural structures evolved independently in songbirds, parrots, and hummingbirds (Nottebohm, 1972, 1980; Brenowitz, 1991; 1997; Margoliash et al., 1994; Striedter, 1994).

The use of cDNA cloning and in situ hybridization techniques in combination with the study of alert behaving animals has recently allowed a high-resolution mapping of brain areas involved in perceptual and motor aspects of vocal communication in songbirds. This approach generated new insights into the functional organization of the song system that were not readily apparent from electrophysiological or anatomical studies alone (reviewed by Clayton, 1997; Ball and Gentner, 1998; Mello, 1998). Specifically, expression analysis of the transcriptional regulators ZENK (Mello et al., 1992; Mello and Clayton, 1994; Jarvis and Nottebohm, 1997), c-jun (Nastiuk et al., 1994), and c-fos (Kimbo and Doupe, 1997) has shown a clear separation of brain areas that have gene activation following song perception or production (Jarvis and Nottebohm, 1997). The auditory ZENK response is species-specific (Mello et al., 1992), is tuned to specific features of song (Ribeiro et al., 1998), occurs mainly with novel song stim-

\begin{tabular}{|c|c|c|c|}
\hline \multicolumn{4}{|c|}{ Abbreviations } \\
\hline A & archistriatum & LH & lamina hyperstriatica \\
\hline AAc & central nucleus of the anterior archistriatum & LL & lateral lemniscus \\
\hline AAcd & dorsal subdivision of AAc & LMD & dorsal medullary lamina \\
\hline AAcv & ventral subdivision of AAc & LPO & lobus parolfactorius \\
\hline $\mathrm{ACM}$ & caudomedial archistriatum & LPOm & magnocellular nucleus of the parolfactory lobe \\
\hline Aivm & ventromedial nucleus of the intermediate archistriatum & M & midbrain \\
\hline Area $\mathrm{X}$ & area $\mathrm{X}$ of the paleostriatum & MAN & magnocellular nucleus of the anterior neostriatum \\
\hline Av & nucleus avalanche & MLd & dorsal part of the lateral mesencephalic nucleus \\
\hline Bas & nucleus basalis & $\mathrm{N}$ & neostriatum \\
\hline $\mathrm{CA}$ & commissura anterior & NAo & oval nucleus of the anterior $\mathrm{N}$ within the NAo complex \\
\hline $\mathrm{Cb}$ & cerebellum & NAoc & NAo complex, vocal anterior neostriatal field including and sur- \\
\hline CLHV & caudolateral hyperstriatum ventrale & & rounding NAo \\
\hline CMHV & caudomedial hyperstriatum ventrale & NAom & region medial and ventrally adjacent to NAo \\
\hline DIP & dorsointermediate nucleus of the posterior thalamus & NAs & the subcentral nucleus of the anterior neostriatum \\
\hline DLM & medial nucleus of the dorsolateral thalamus & $\mathrm{NC}$ & caudal neostriatum \\
\hline DLP & dorsolateral nucleus of the posterior thalamus & $\mathrm{NCM}$ & caudomedial neostriatum \\
\hline DMA & dorsomedial nucleus of the anterior thalamus & $\mathrm{NF}$ & frontal neostriatum \\
\hline DM & dorsomedial nucleus of ICo & $\mathrm{Ndc}$ & dorsocaudal neostriatum \\
\hline $\mathrm{DMm}$ & magnocellular nucleus of the dorsomedial thalamus & NIf & nucleus interfacialis \\
\hline DMP & dorsomedial nucleus of the posterior thalamus & NLc & central nucleus of the lateral neostriatum \\
\hline $\mathrm{E}$ & ectostriatum & NLs & supracentral nucleus of the lateral neostriatum \\
\hline ex & extensions of LPOm & NLv & ventral nucleus of the lateral neostriatum \\
\hline FPL & lateral forebrain bundle & nXIIts & tracheosyringeal portion of the hypoglossal nucleus \\
\hline HA & hyperstriatum accessorium & $\mathrm{OC}$ & optic chiasma \\
\hline $\mathrm{HD}$ & hyperstriatum dorsale & Ov & nucleus ovoidalis \\
\hline Hр & hippocampus & $\mathrm{P}$ & paleostriatum \\
\hline $\mathrm{HV}$ & hyperstriatum ventrale & $\mathrm{PA}$ & paleostriatum augmentatum \\
\hline HVC & high vocal center & PC & caudal paleostriatum \\
\hline HVo & oval nucleus of the anterior HV within the HVo complex & PP & paleostriatum primitivum \\
\hline HVoc & HVo complex, vocal anterior-medial hyperstriatal ventrale field & $\operatorname{PrV}$ & principal sensory nucleus of the trigeminal nerve \\
\hline & including and surrounding $\mathrm{HVo}$ & RA & robust nucleus of the archistriatum \\
\hline ICo & intercollicular nucleus & RAm & nucleus archistriatalis rostromedialis \\
\hline $\mathrm{L}$ & field $\mathrm{L}$ complex in the caudal telencephalon & Rt & nucleus rotundus \\
\hline $\mathrm{L} 1, \mathrm{~L} 2, \mathrm{~L} 3$ & subdivisions of field $\mathrm{L}$ & $\mathrm{SpL}$ & nucleus spiriformis lateralis \\
\hline LAD & lamina archistriatalis dorsalis & $\mathrm{T}$ & thalamus \\
\hline lAHV & lateral nucleus of the anterior hyperstriatum ventrale & $\mathrm{TeO}$ & optic tectum \\
\hline $1 \mathrm{AN}$ & lateral nucleus of the anterior neostriatum & tOM & tractus occipitomesencephalicus \\
\hline LF & lamina frontalis & $\mathrm{tOv}$ & tractus ovoidalis \\
\hline
\end{tabular}


uli (Mello et al., 1995; Jarvis et al., 1995), and requires early juvenile experience with adult tutors (Jin and Clayton, 1997). The vocal gene response is dependent on behavioral context (Jarvis et al., 1998) and differs for different genes (Jarvis and Nottebohm, 1997; Kimbo and Doupe, 1997).

The purpose of the present study is to determine whether the phenomenon of auditory and vocal brain gene regulation also occurs in another vocal learning order, i.e., parrots, and, if it does, to use it to map auditory and vocal control centers in this bird group. Here we show that, when budgerigars (Australian parakeets) hear conspecific songs (warbles), ZENK is induced in the caudomedial forebrain and within the midbrain, but not elsewhere. In contrast, when budgerigars engage in active vocalizing, ZENK is induced in nine other distinct brain structures. Seven of these had been previously described as part of the circuitry that projects onto motor neurons of the tracheosyringeal nerve; two others are located in an area known to receive auditory information. The ZENK expression patterns revealed broader anatomical boundaries than previously described. These results have allowed us to generate a functional brain map of areas involved in parrot vocal communication and to address further the neurobiological basis of the evolution of vocal learning.

\section{MATERIALS AND METHODS Behavioral paradigm}

Ten adult male budgerigars, approximately 1 year old, were purchased from a local breeder (Englishtown, NJ) and housed in groups of two or three birds per cage for several weeks. During this period, the animals became familiar with their new environment and gradually increased the amount of their spontaneous vocalizations, i.e., songs (warbles) and calls. A stimulus tape of the warbles was generated as follows. A group of birds in a cage was initially recorded every time they warbled. The next day, the warbles were played back to the same birds. This induced more warbling behavior, which was again recorded to generate a second tape. A segment of the second tape containing about 10 minutes of continuous warbling, when played back to the same or other birds, was particularly effective at stimulating more warbling than the first tape and was used as the playback stimulus.

On the day of the experiment, groups of two or three birds at a time were prevented from vocalizing (calls and warbles) for a 2-3 hour period by the presence of an investigator next to the cage. Whenever a bird appeared to make an attempt to vocalize (by assuming a characteristic posture and opening the bill) the investigator would make some movement, which prevented the bird from vocalizing. Within a short interval thereafter (10-20 minutes), the birds typically stopped making attempts to vocalize. In songbirds, this procedure was found to reduce ZENK mRNA expression in vocal and auditory areas to levels comparable to those in birds that naturally remain silent for the same period of time (Jarvis and Nottebohm, 1997). After the 2-3 hour quiet period, budgerigars were presented with a playback of the recorded warbles for 30 minutes (three repetitions of the selected 10 minute segment). The birds were divided into two groups according to their natural behavioral response: those that responded by warbling (hearing and vocalizing; $\mathrm{n}=4$ ) and those that remained silent (hearing only; $\mathrm{n}=3$ ). Separately, quiet controls $(\mathrm{n}=2)$ did not hear any playbacks and naturally did not vocalize for a 1.5 hour period after initially being prevented from doing so by the presence of the investigator for 30 minutes. These birds were killed immediately at the end of the total 2 hour quiet period. An additional animal was prevented from vocalizing for the full 2 hours without any playback and was added to the quiet control group ( $\mathrm{n}=3$ total). The ZENK expression pattern in vocal and auditory nuclei of this last animal was essentially the same as that of birds who naturally remained silent; however, expression in a number of other brain areas outside the auditory and vocal pathways was high relative to all other birds (not shown). The stimulation sessions were videotaped and reexamined to confirm the bird's behavioral responses and to calculate the amount of warble song bouts and calls made by each bird in the hearing and vocalizing group. One warble bout was defined as a vocalization that lasted between 1 and 10 seconds. If a bird continued to warble for more than 10 seconds, then one bout was given to every 10 seconds of that continuous warbling. For some birds, bouts of continuos warbling lasted between 30 seconds and 5 minutes. At the end of each stimulation session, birds were immediately killed by decapitation, and their brains were quickly dissected, covered with TissueTek (Miles, Ekhart, IL), and frozen in an ethanol/dry ice bath. This protocol was approved by the animal care and use committee at the Rockefeller University.

\section{Gene expression analysis}

Brains were sectioned on a cryostat at a $10 \mu \mathrm{m}$ thickness and stored at $-70^{\circ} \mathrm{C}$. Sections were then processed for in situ hybridization with a ${ }^{35} \mathrm{~S}$-labeled riboprobe synthesized from a cloned canary ZENK cDNA, using a previously described protocol (Mello et al., 1997). ZENK is an acronym for the gene known in mammalian species as Zif-268, Egr-1, NGFI-A, and Krox24 (Mello et al., 1992). Initially, tests were conducted by varying the hybridization and wash temperatures to determine the adequate stringency for cross-reaction to budgerigar ZENK mRNA. Canary brain sections from our collection were included as positive controls. A high-stringency hybridization temperature $\left(65^{\circ} \mathrm{C}\right)$ and wash protocol $\left(0.1 \times \mathrm{SSPE}\right.$ at $\left.65^{\circ} \mathrm{C}\right) \mathrm{re}-$ sulted in specific cellular labeling for the ZENK antisense riboprobe with similar intensity for both budgerigar and canary brain sections and no labeling for the sense riboprobe (not shown). This result supports recent findings showing that the ZENK gene is well conserved among avian orders and cross-hybridizes among them (Long and Salbaum, 1998).

The right brain hemisphere of one bird from each group was cut in the parasagittal plane and the left in the frontal plane. Sections were cut in series such that one section every $200 \mu \mathrm{m}$ (totaling 52 sections in the parasagittal plane and 114 in the frontal plane per bird) was hybridized in one experimental reaction. Positive signal was first detected by PhosphorImager analysis (Molecular Dynamics, Sunnyvale, CA); slides were then dipped in autoradiographic emulsion (NTB2; Kodak) and exposed for 4 weeks at $4^{\circ} \mathrm{C}$. After developing, sections were Nissl stained with $0.3 \%$ cresyl violet acetate (Sigma, St. Louis, MO) to help identify brain subdivisions and nuclei. After areas of gene activation were determined in this initial series, it was decided to cut the remaining brains from each group in the 


\section{QUIET CONTROL}

\section{A}
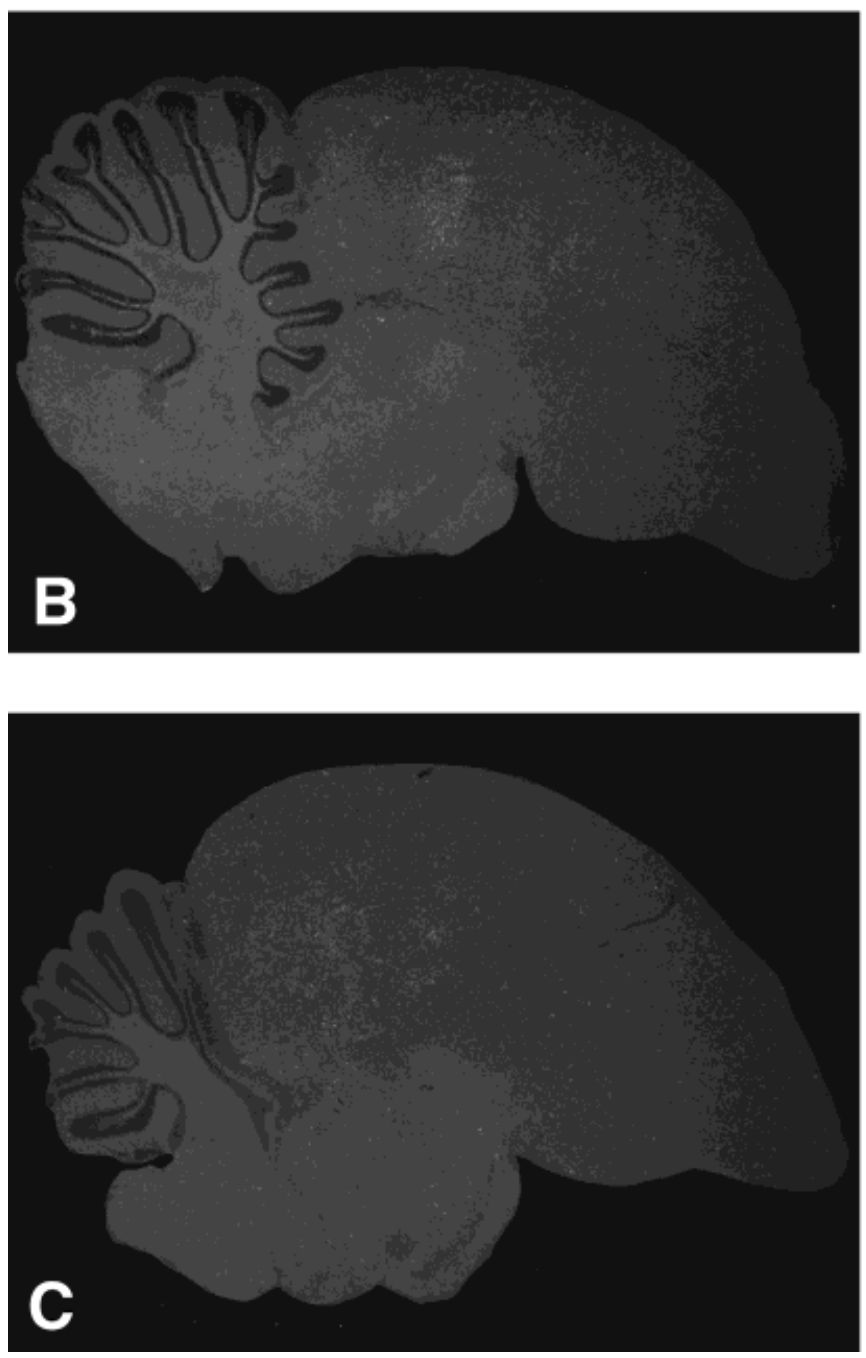

Fig. 2. Hearing- and vocalizing induced ZENK gene expression in the budgerigar brain, parasagittal series. A-G: Darkfield views of serial parasagittal brain sections hybridized to a radioactively labeled canary ZENK riboprobe. Birds were in silence for 2 hours (quiet control; first column), heard warble song for 30 minutes (hearing only; second column), or heard song and continuously vocalized in response for 30 minutes (hearing and vocalizing; third column). Nissl staining appears as grey and areas of ZENK expression as white (silver grains over labeled tissue). The images shown are from one representative bird from each group (right hemisphere). Camera lucida drawings of

\section{HEARING ONLY}
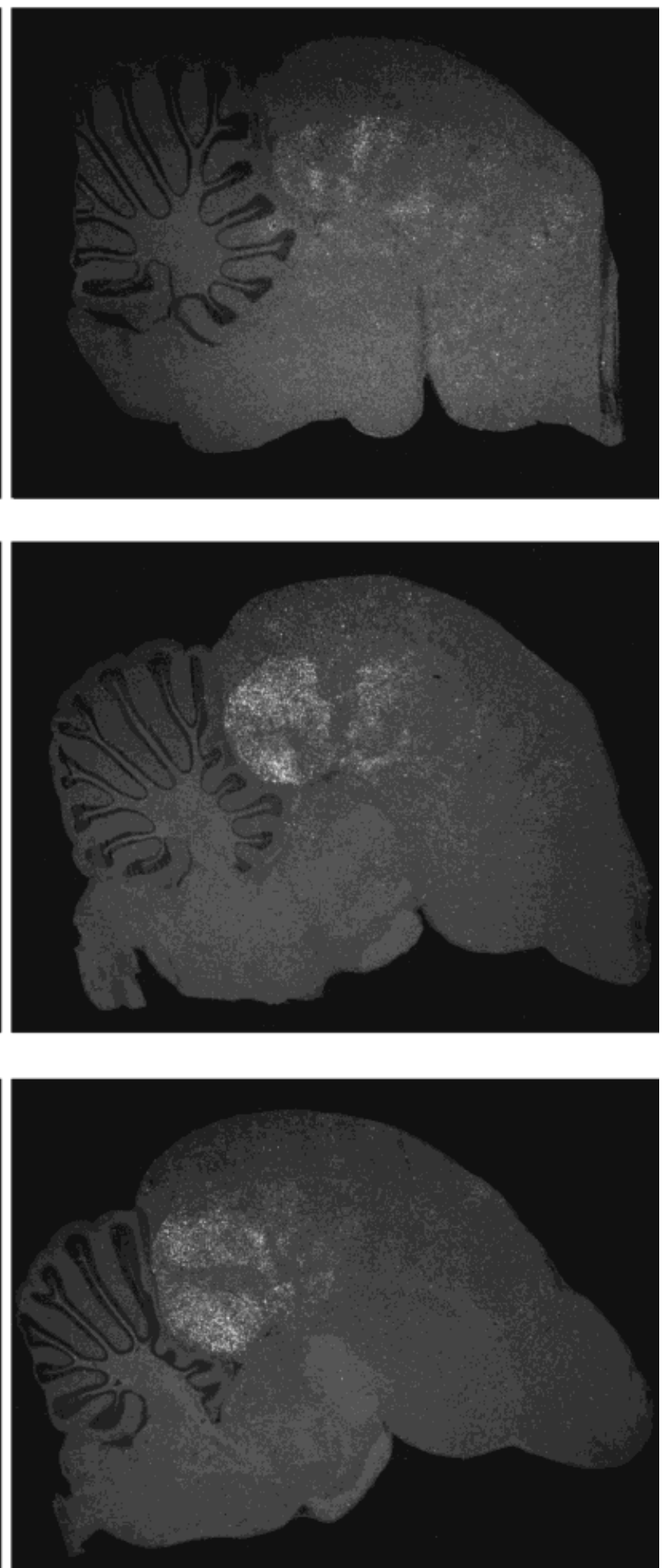

Nissl-stained reference sections from the hearing and vocalizing bird are shown in the fourth column; solid lines indicate Nissl-defined boundaries; dashed lines indicate boundaries of hearing- or vocalizing-induced ZENK expression. The first section for each column is at about $0.36 \mathrm{~mm}$ from the midline; each subsequent section is about $0.72 \mathrm{~mm}$ farther laterally. Large arrows above the camera lucida drawing (A) indicate the position of the first (rostral) and last (caudal) sections cut in the frontal plane of Figure 3. Orientation: dorsal is up and anterior to the right. Scale bars $=2 \mathrm{~mm}$. 


\section{HEARING \& VOCALIZING}

ANATOMICAL MAP
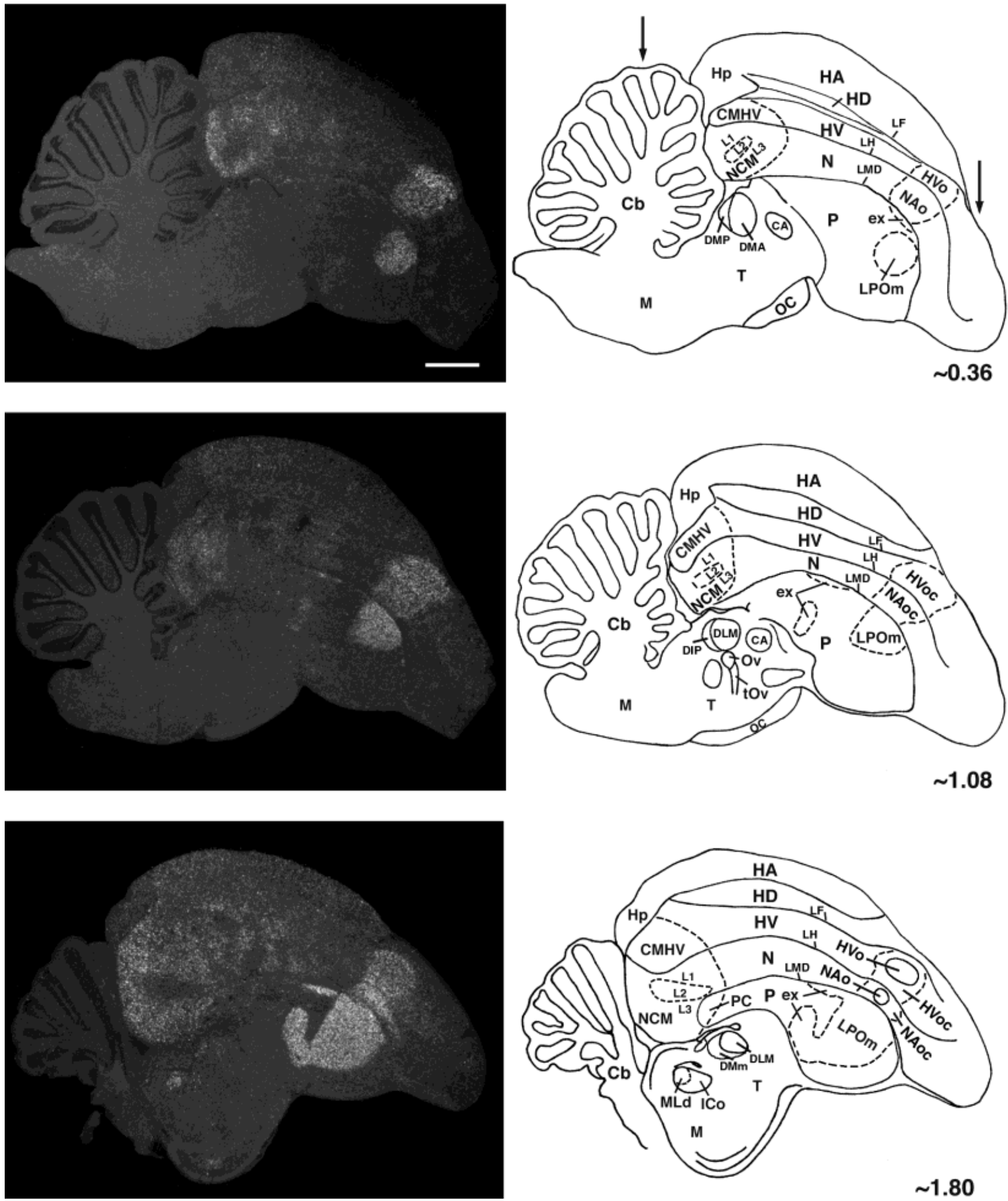

Figure 2 (Continued) 


\section{QUIET CONTROL}
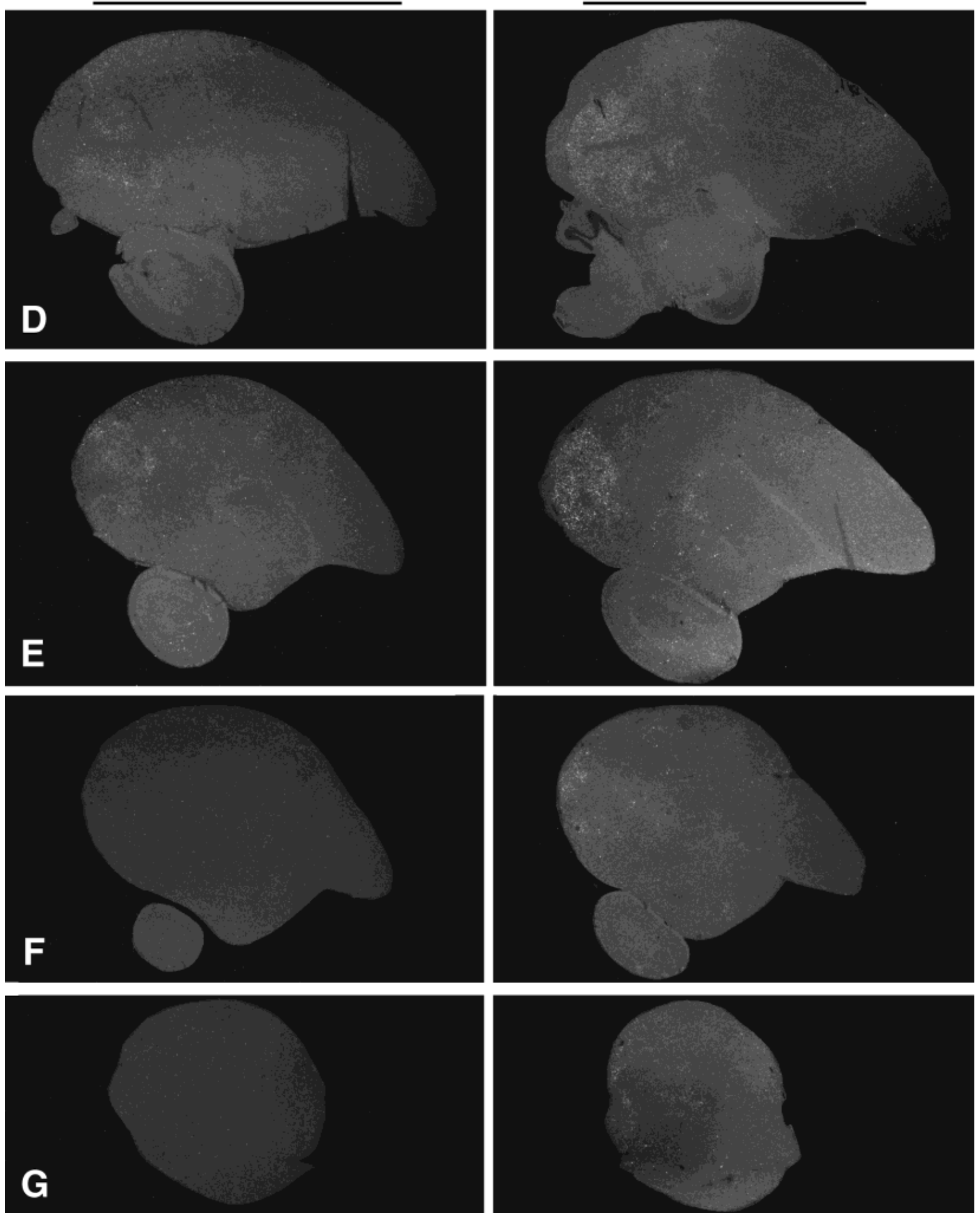

Figure 2 (Continued) 


\section{HEARING \& VOCALIZING}
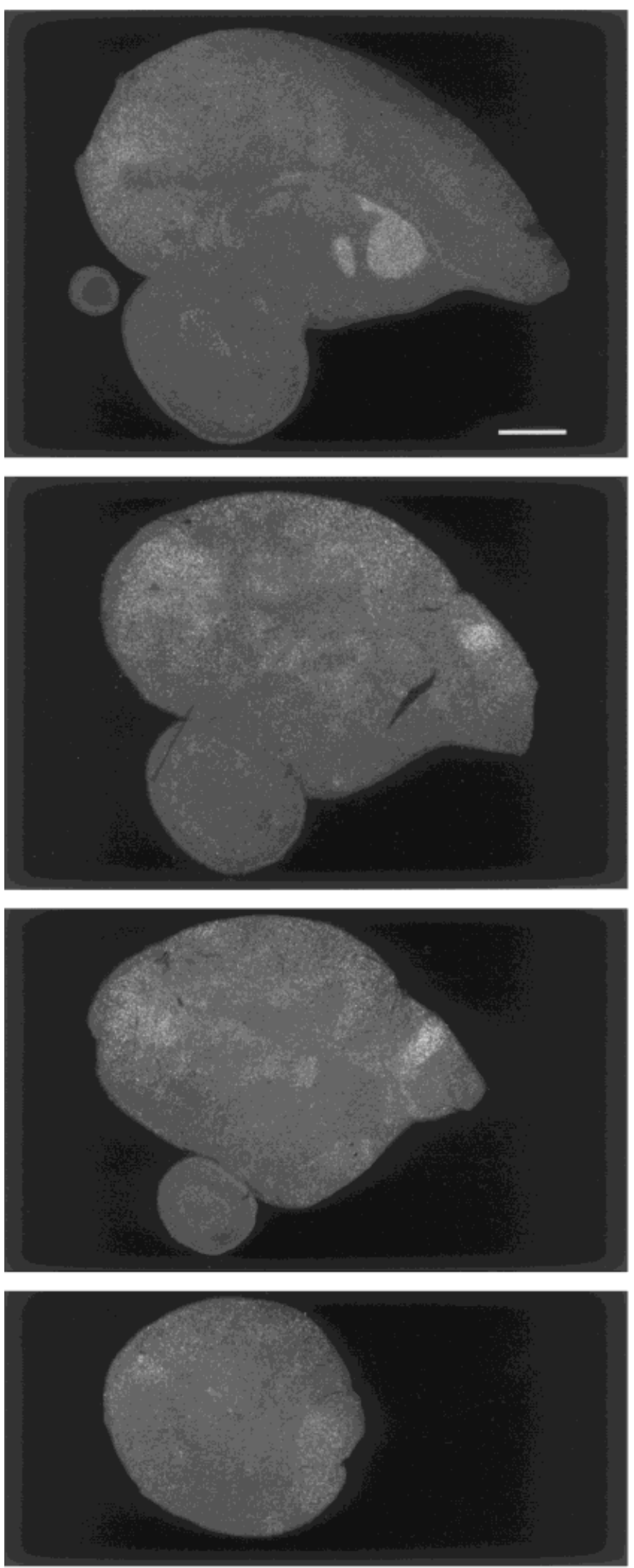

\section{ANATOMICAL MAP}
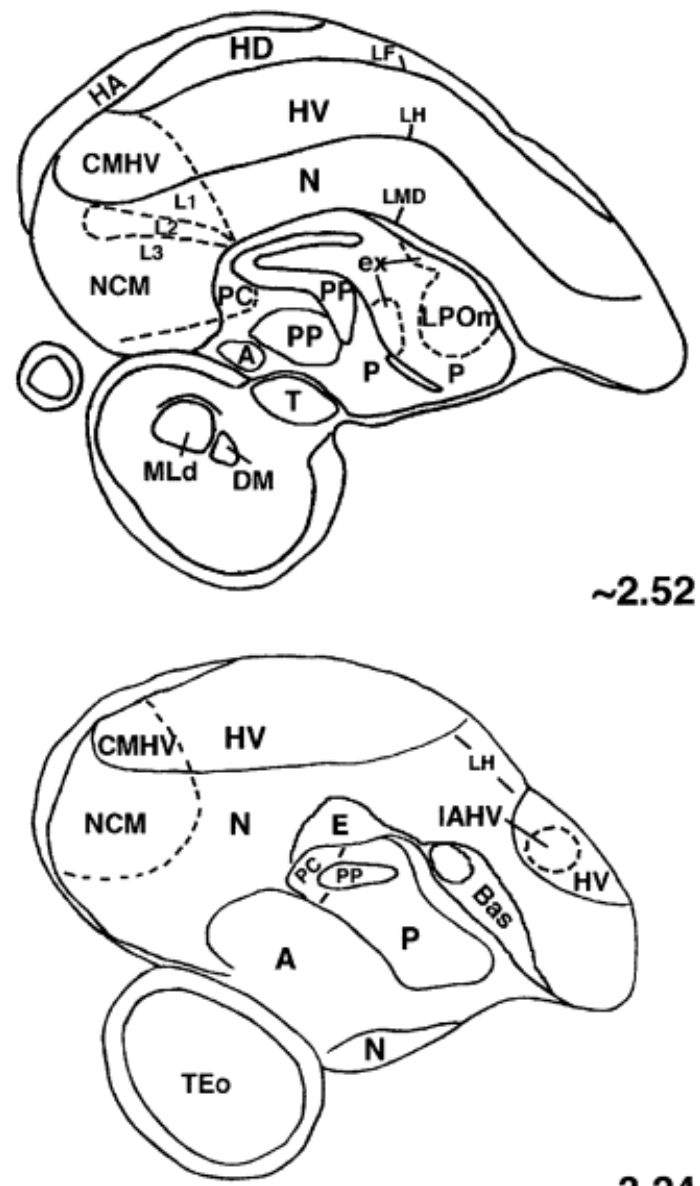

$\sim 3.24$
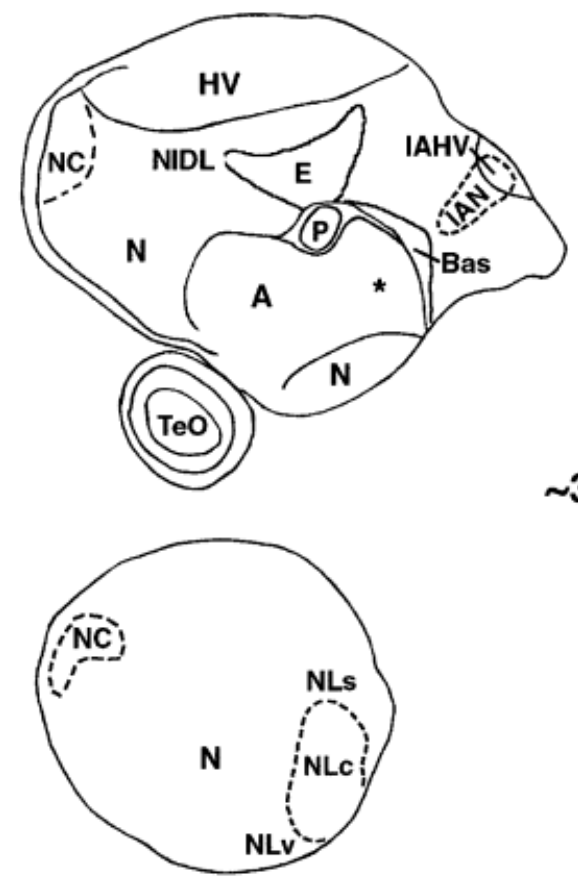


\section{QUIET CONTROL}
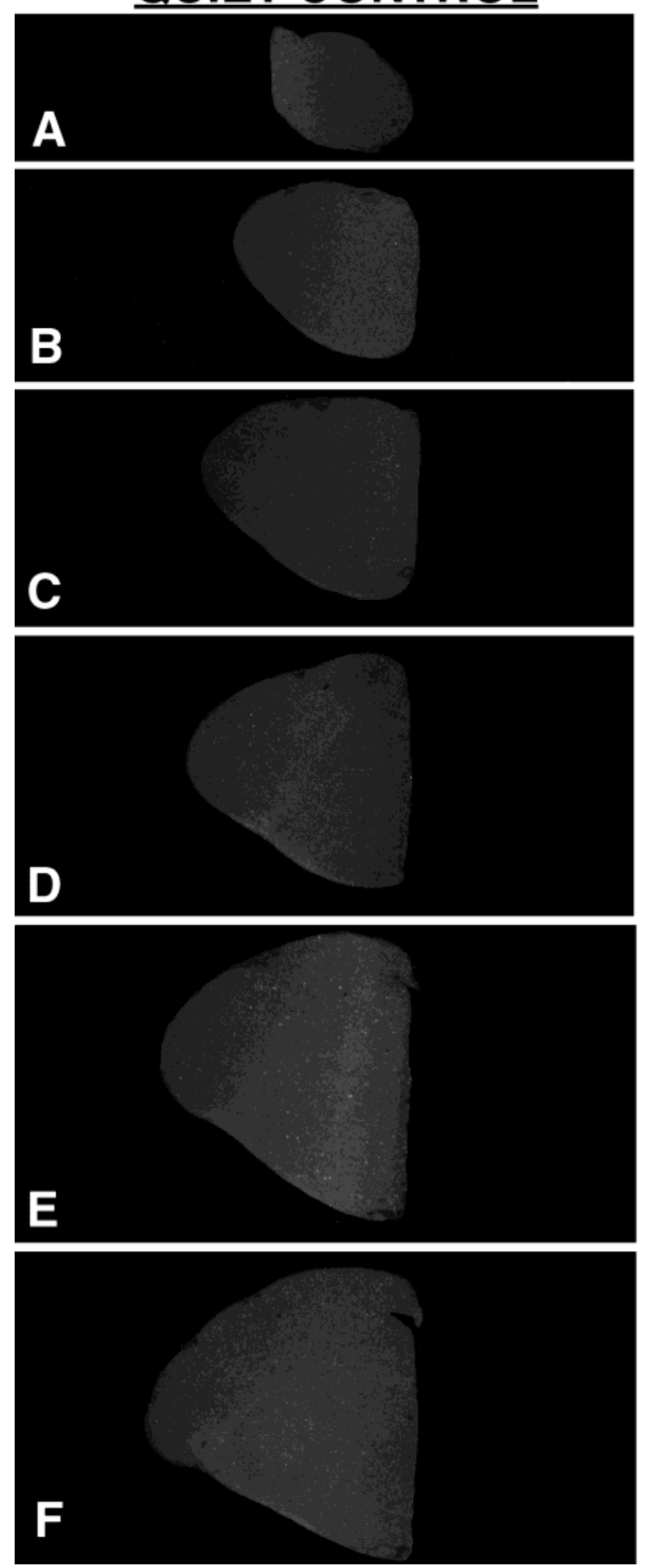

Fig. 3. Hearing- and vocalizing induced ZENK gene expression in the budgerigar brain, frontal series. A-R: Darkfield views of serial frontal brain sections hybridized to a radioactively labeled canary ZENK riboprobe (the left brain hemisphere from the same birds shown in Fig. 2). The first section for each column is at about $7.2 \mathrm{~mm}$

\section{HEARING ONLY}
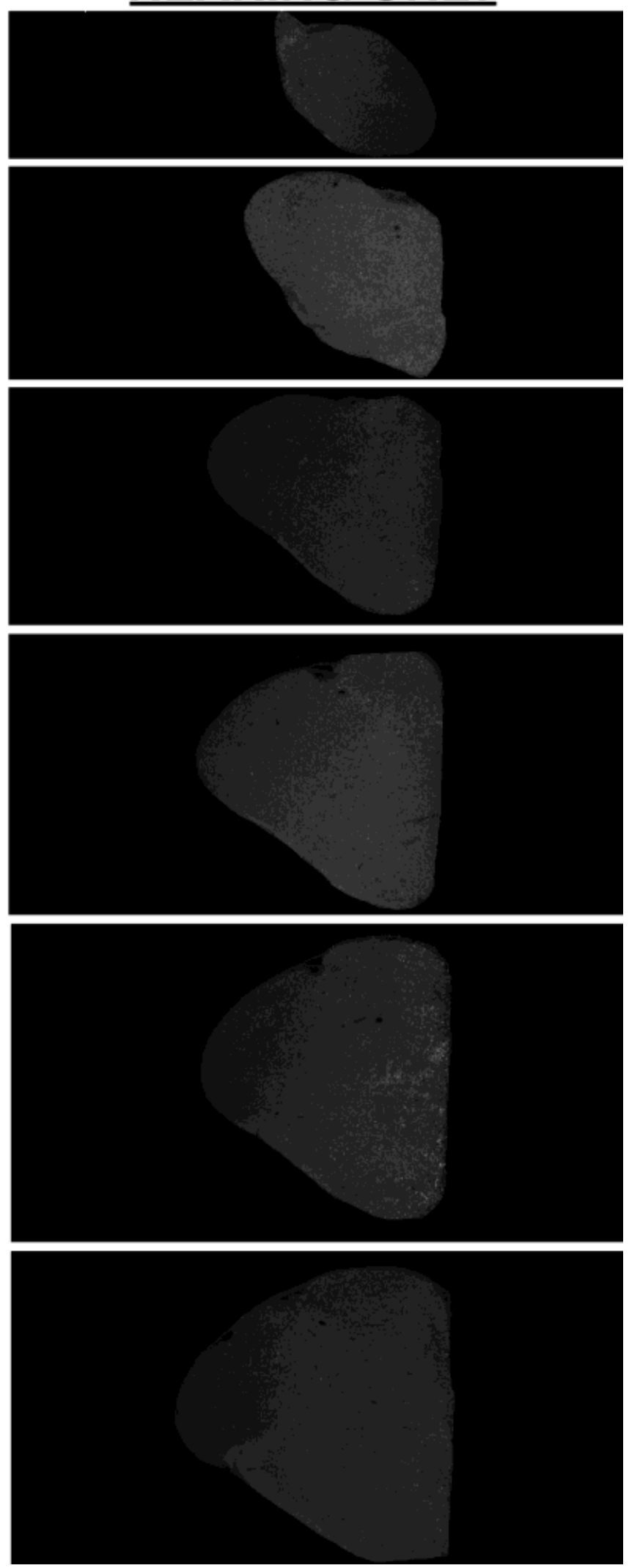

from the stereotaxic zero; each subsequent section is about $0.72 \mathrm{~mm}$ farther caudally. Large double arrows between camera lucida drawings indicate the first (medial) and last (lateral) sections cut in the parasagittal plane of Figure 2. Orientation: dorsal is up and medial to the right. Scale bars $=2 \mathrm{~mm}$. 

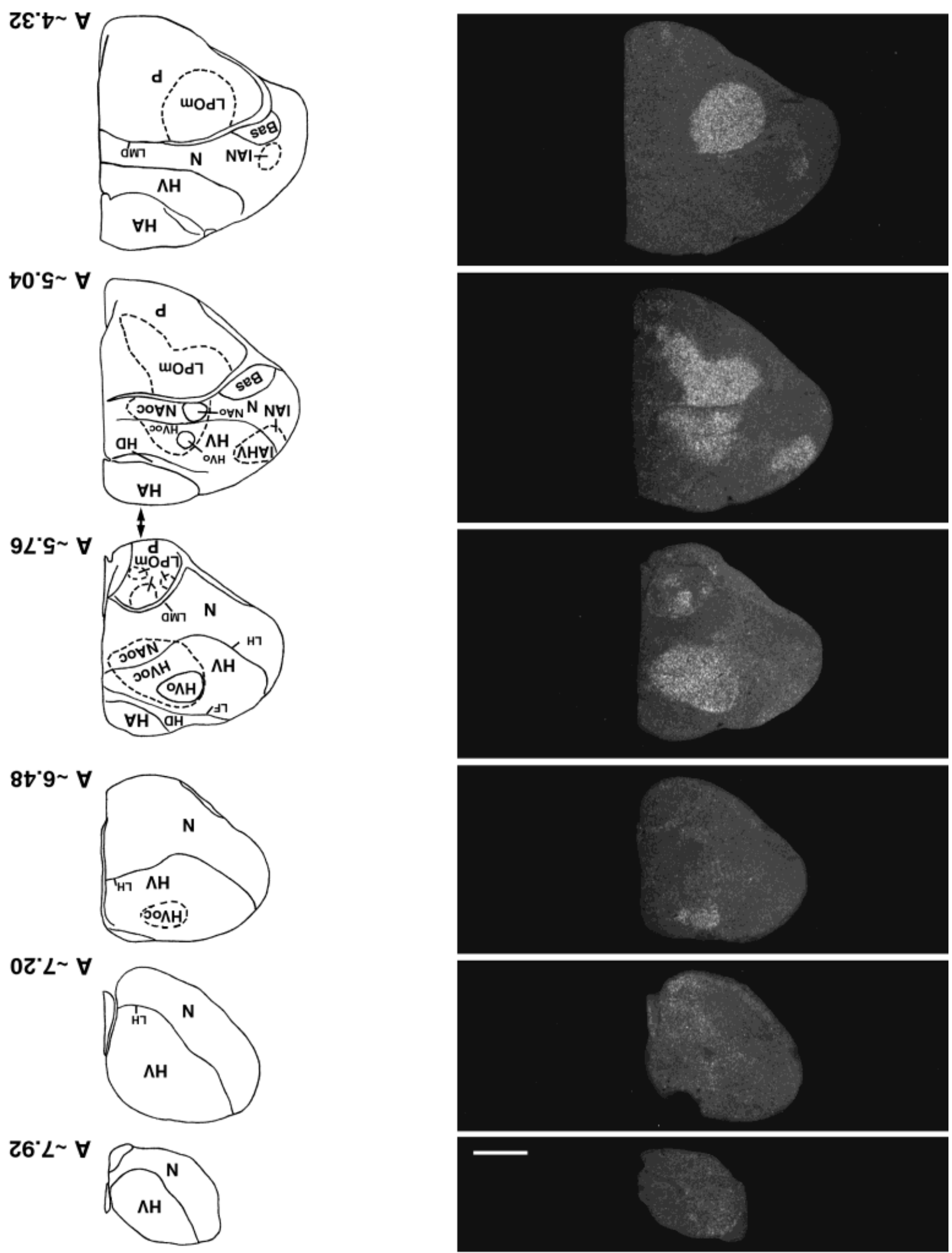

$\overline{d \forall W ~ 7 \forall D I W O \perp \forall N \forall}$
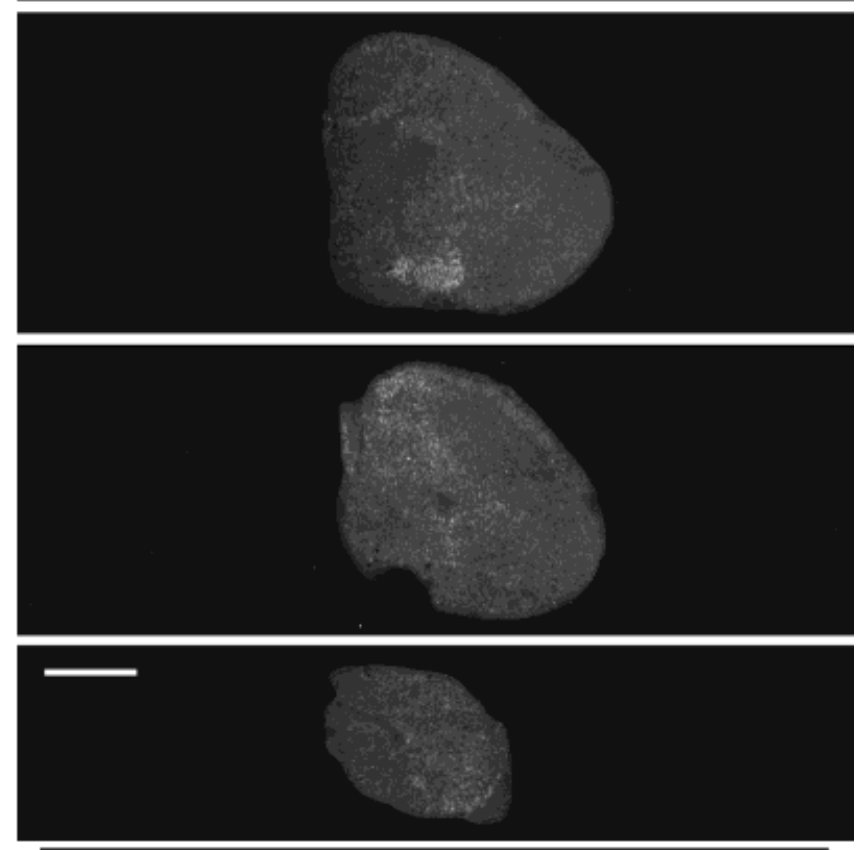

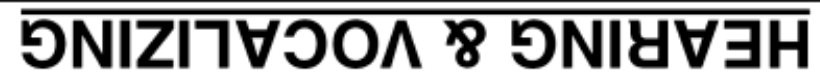

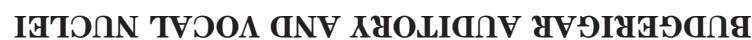




\section{QUIET CONTROL}
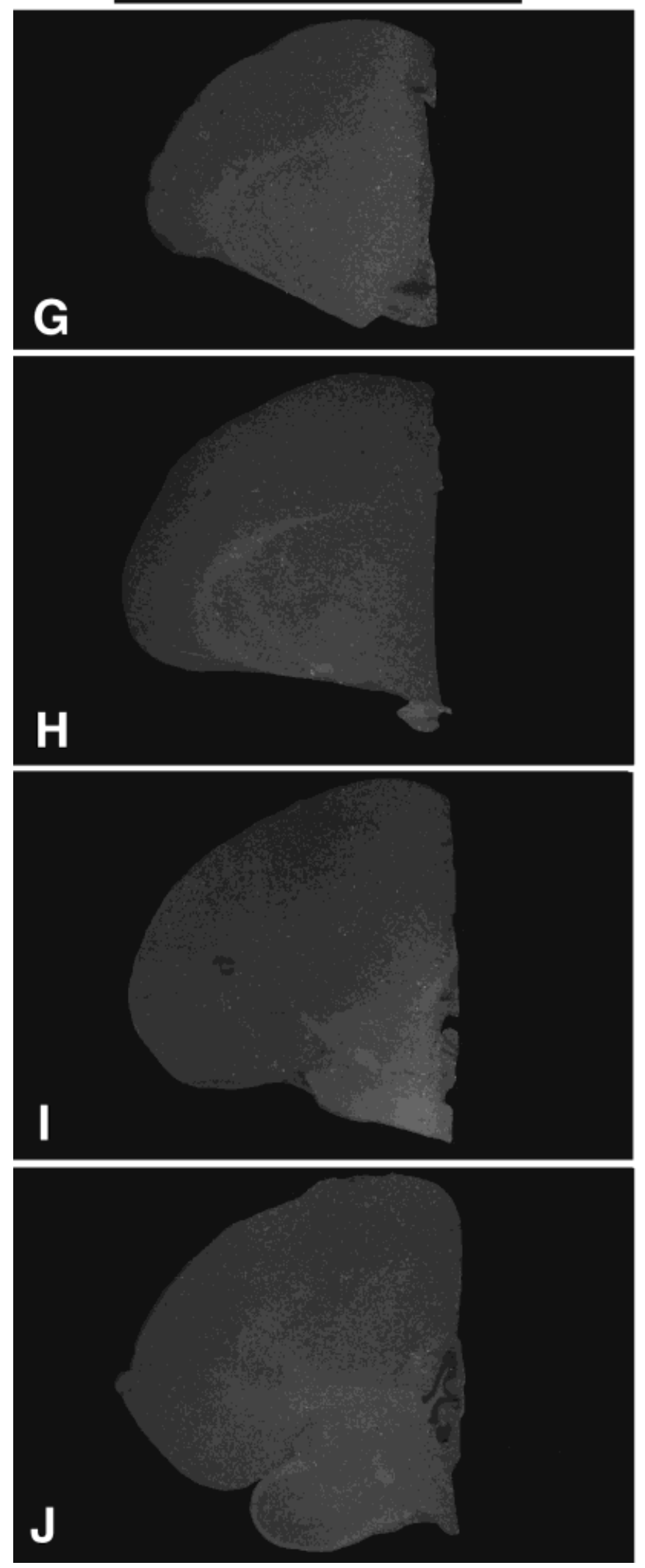

HEARING ONLY
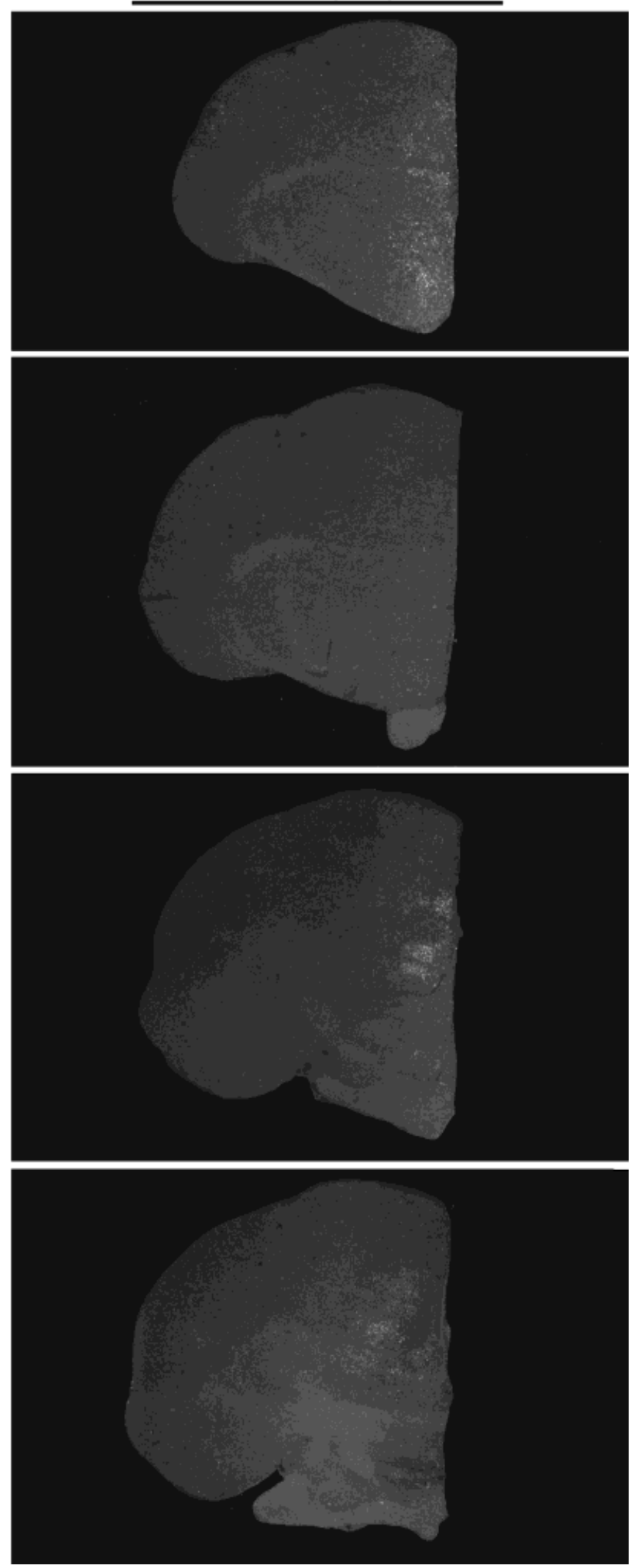


\section{HEARING \& VOCALIZING}
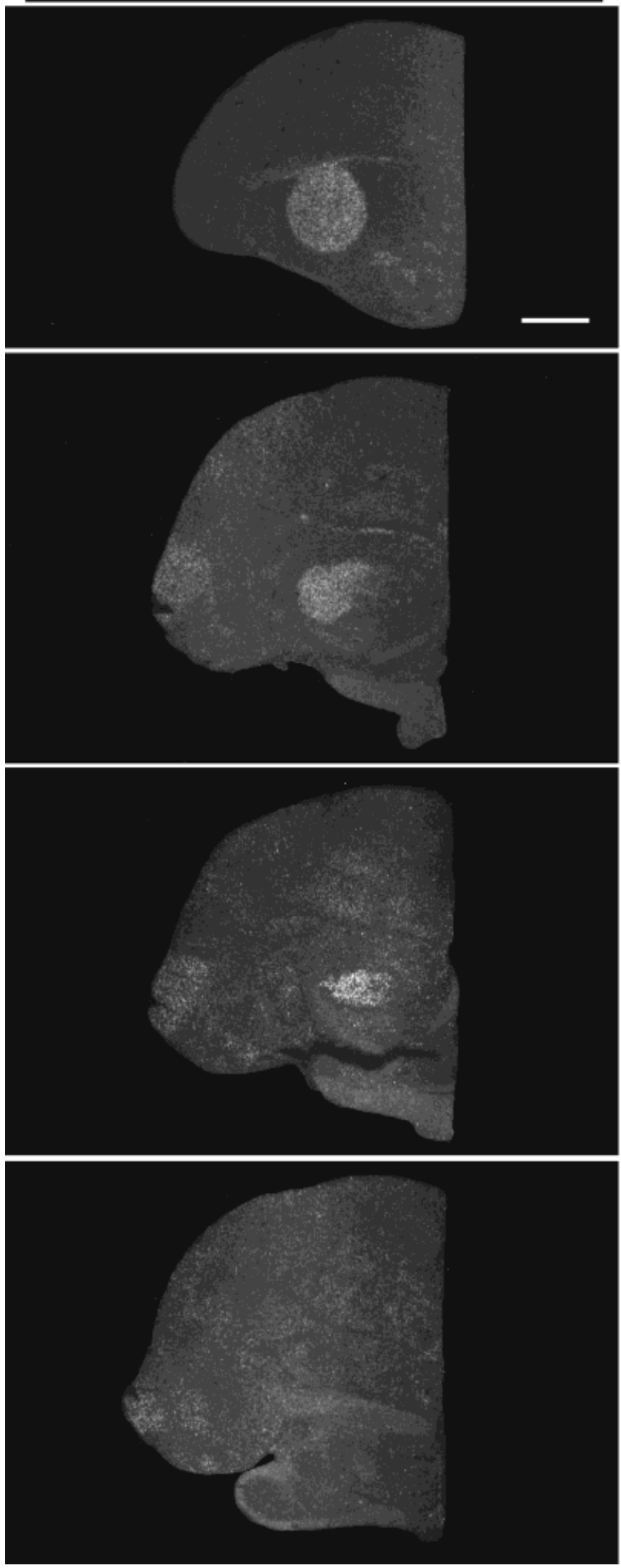

\section{ANATOMICAL MAP}

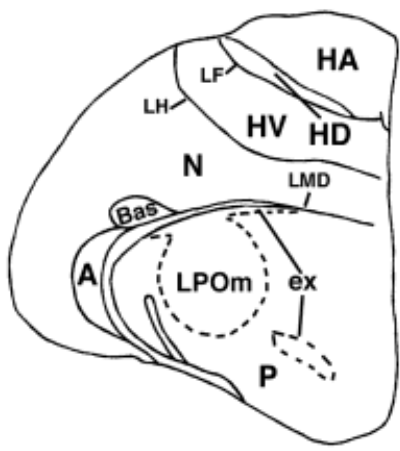

A $\sim 3.60$

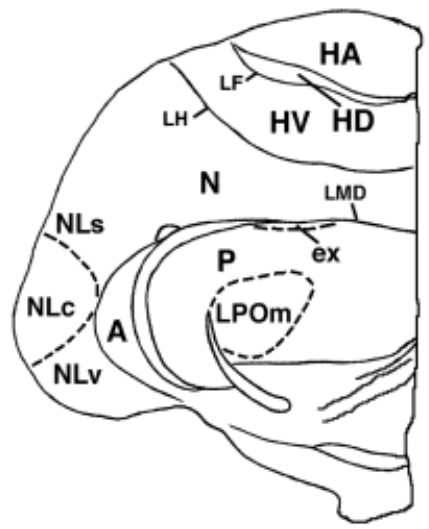

A $~ 2.88$

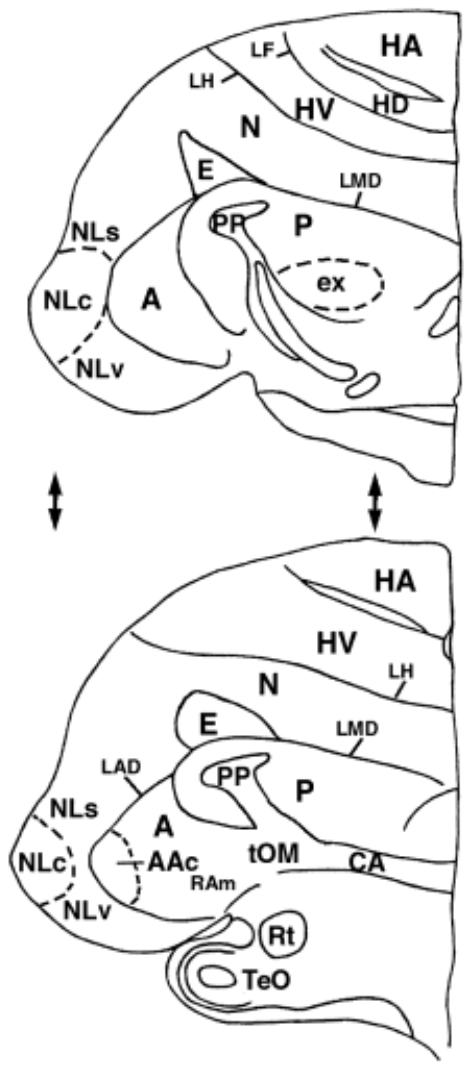

A $\sim 2.28$

A 1.68 


\section{QUIET CONTROL}
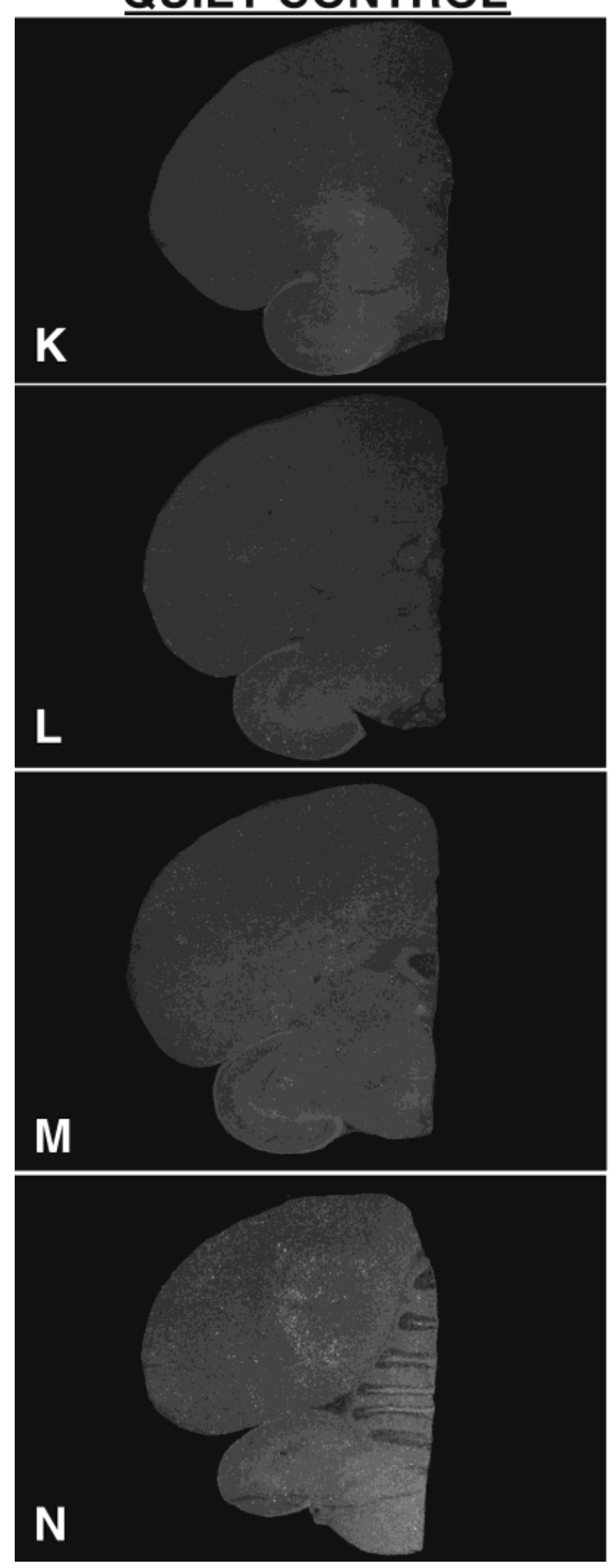

HEARING ONLY
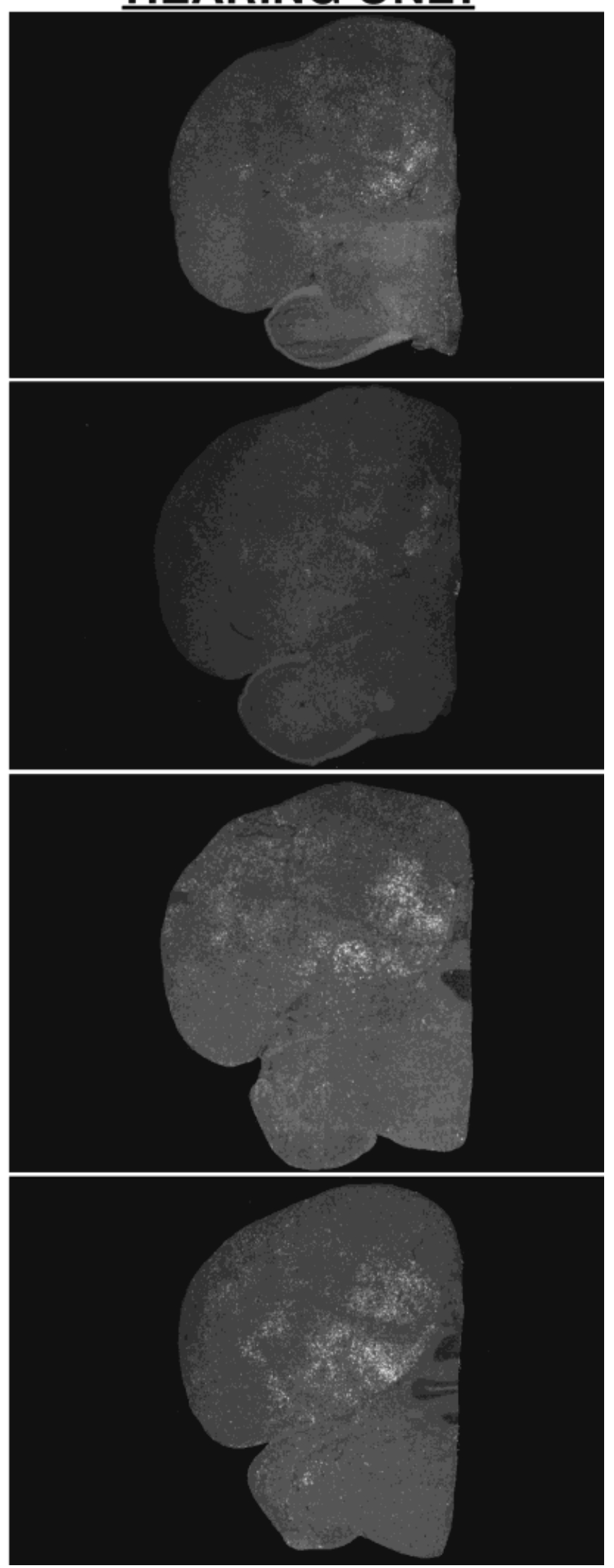


\section{HEARING \& VOCALIZING}
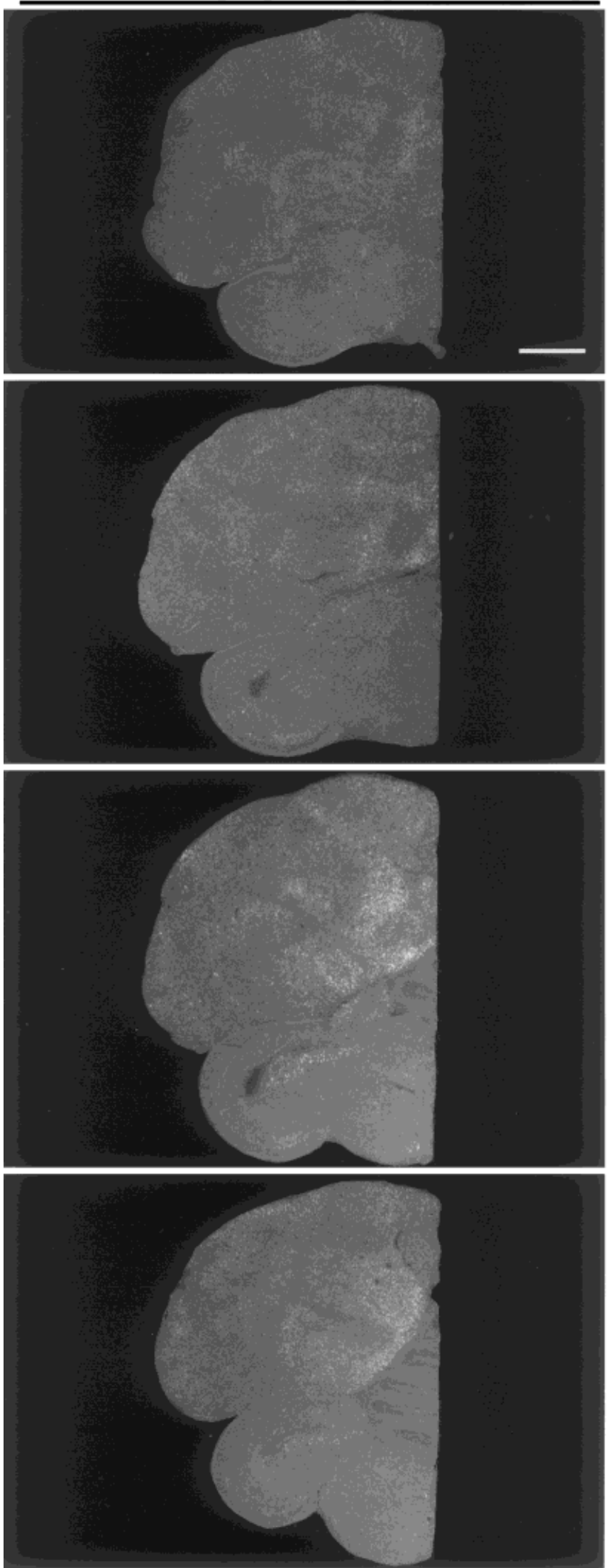

\section{ANATOMICAL MAP}
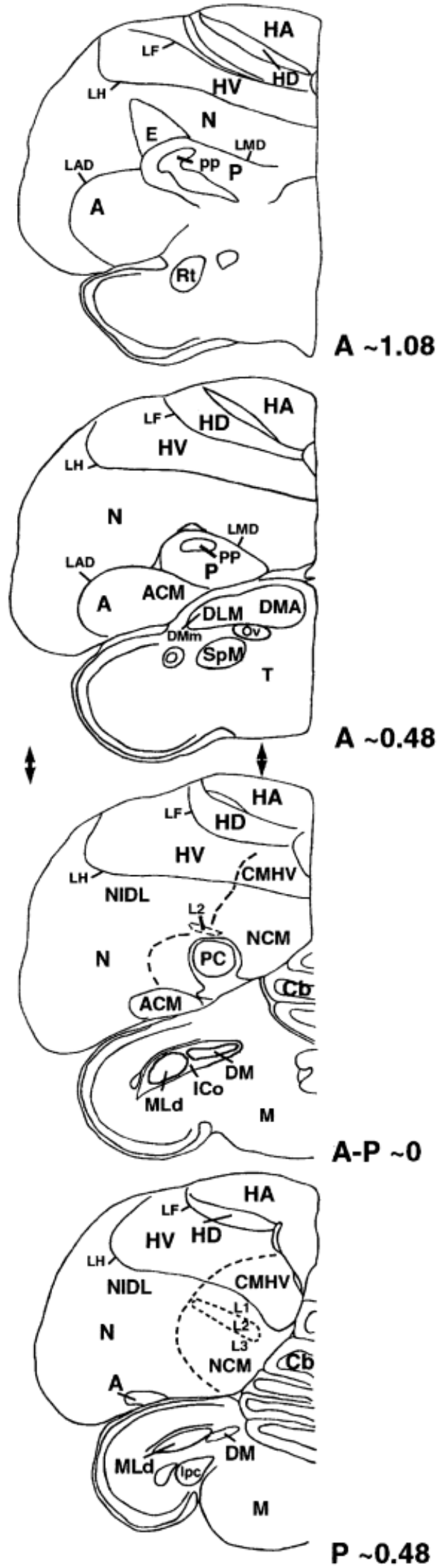


\section{QUIET CONTROL}
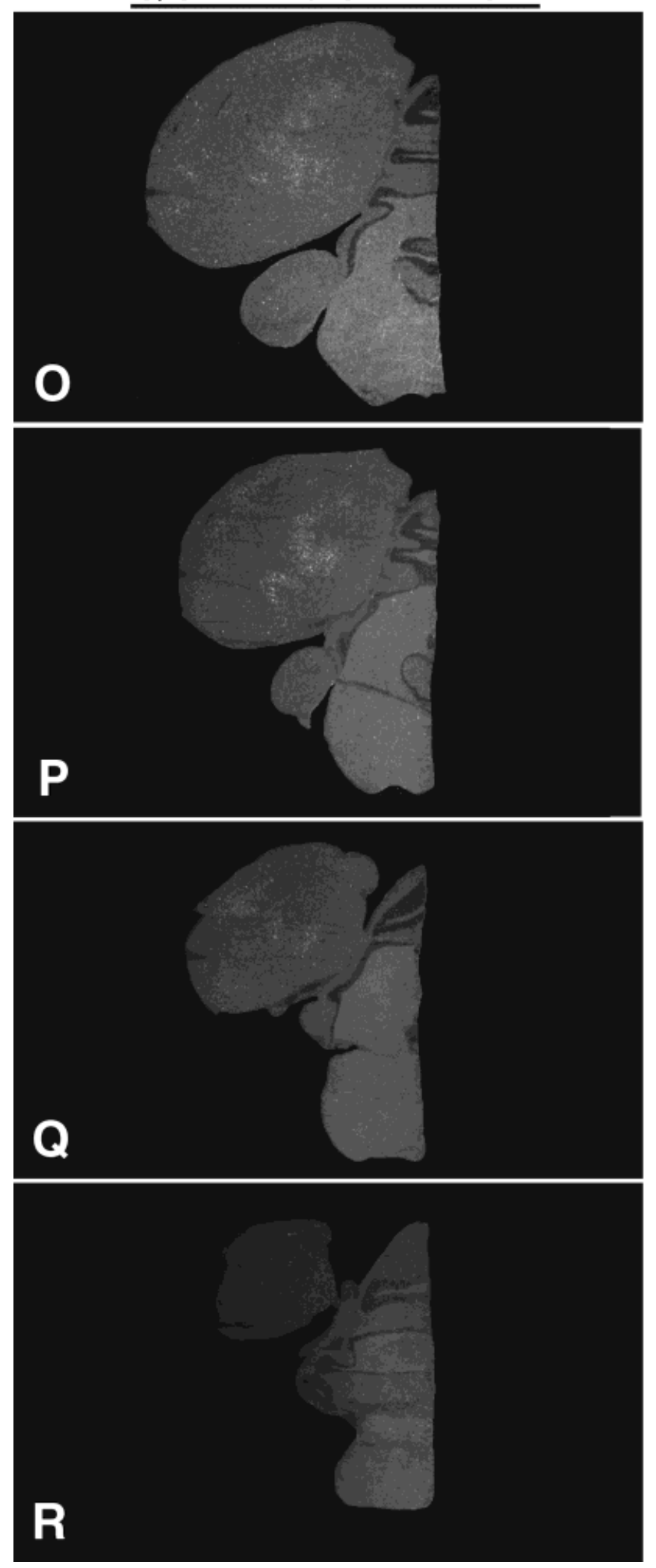

HEARING ONLY
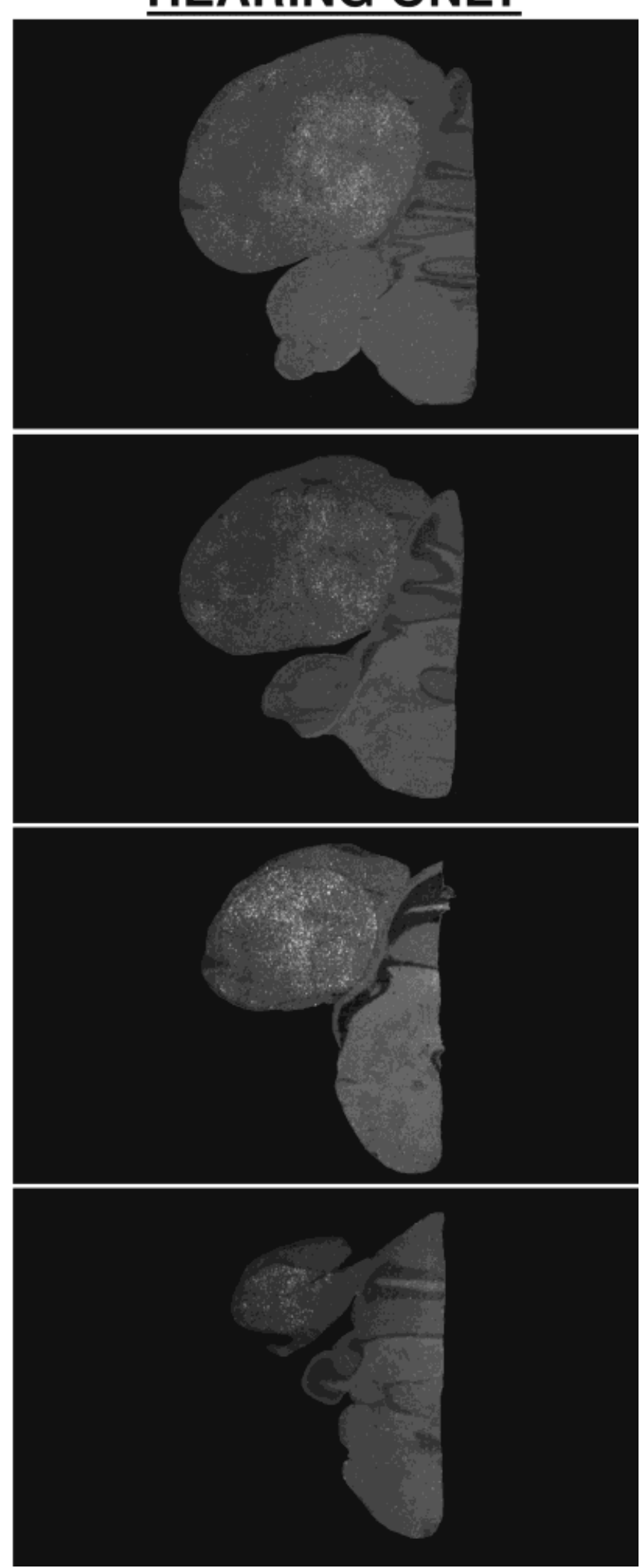


\section{HEARING \& VOCALIZING}
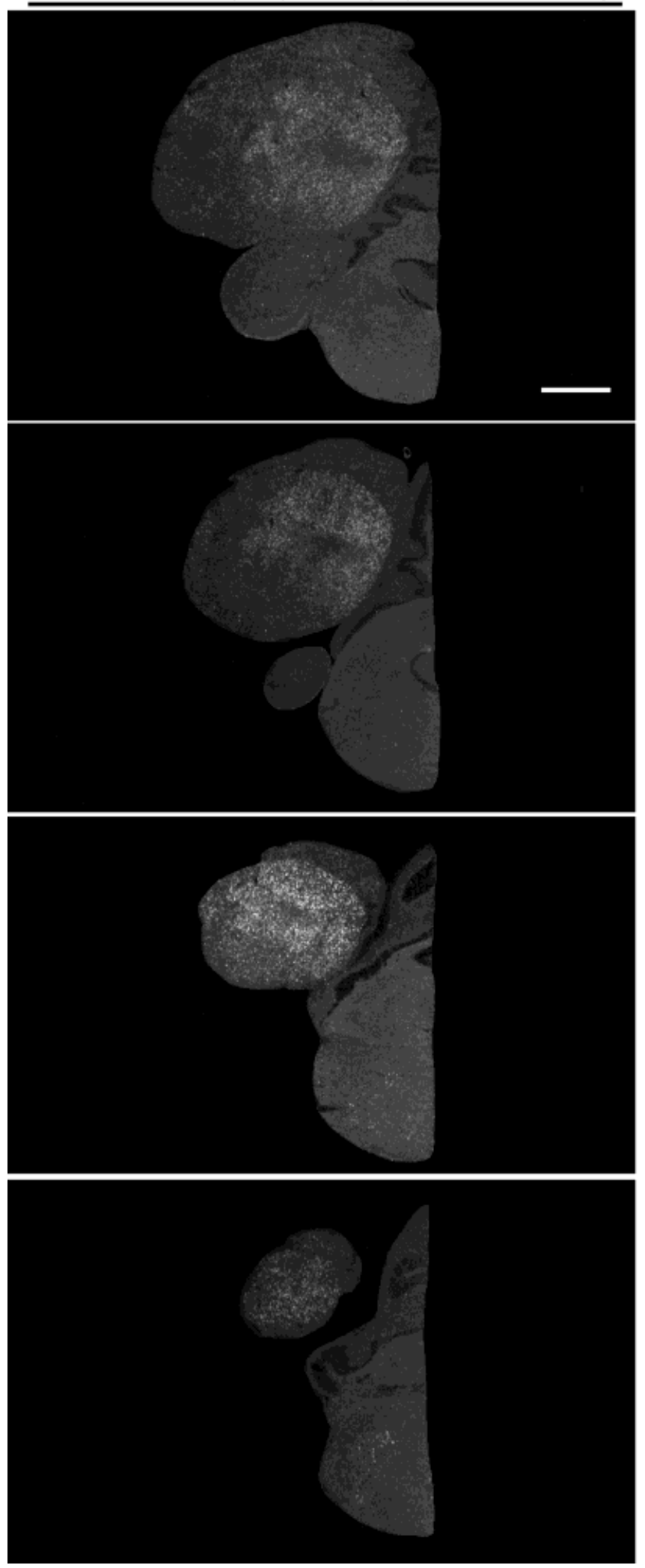

Figure 3 (Continued)
ANATOMICAL MAP
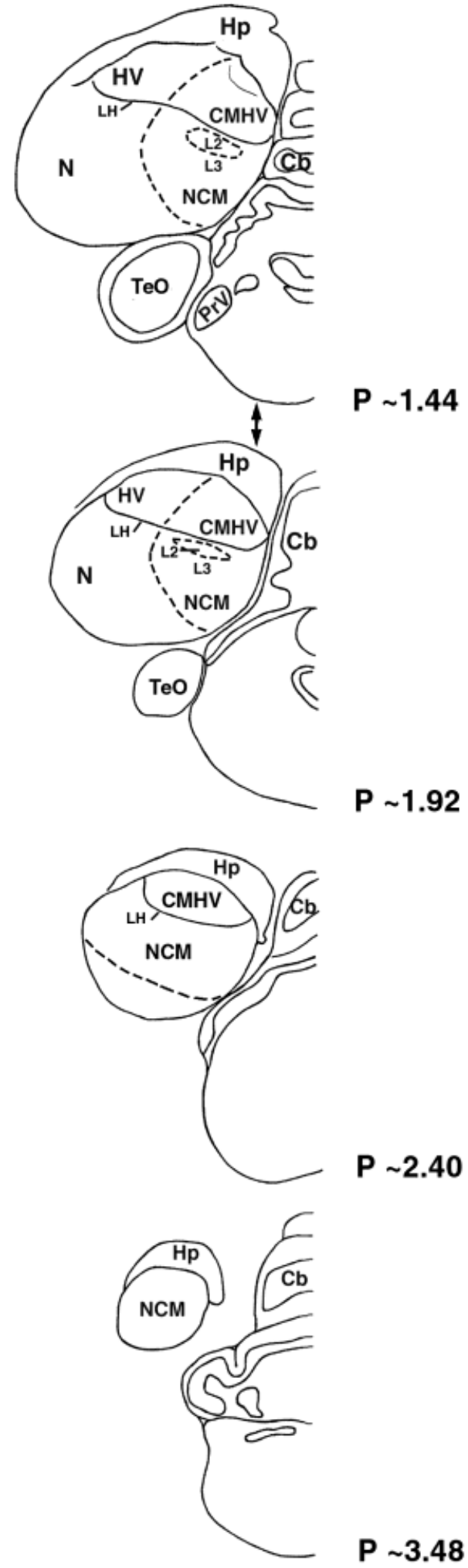
frontal plane in order to confirm the gene expression patterns and to quantify the induced levels for statistical comparisons. The relative level of ZENK gene expression (for Fig. 9) was determined by counting the number of autoradiographic silver grains per cell (in $\sim 50$ cells/brain region/animal minus background on the glass slide) in control vs. stimulated animals using a computer-yoked system as previously described (Jarvis and Nottebohm, 1997; Jarvis et al., 1998). Adjacent unhybridized thicker sections $(20 \mu \mathrm{m})$ were also stained with cresyl violet (Nissl staining) to determine nuclei boundaries independent of gene expression patterns.

\section{Figure preparation}

For darkfield presentations (Figs. 2, 3), slide pictures (35 mm, 64 speed, tungsten color slide film; Kodak) of brain sections were taken underneath a stereo microscope with a fiber optic light source attached to a darkfield converter. Light exposure time was kept constant so that gene expression signal intensity could be visually compared across all sections. After developing, slide pictures were scanned into a computer in gray scale and transferred to Adobe Photoshop (Adobe, San Jose, CA). Slide background outside of the tissue was reduced equally for all brain sections to allow for easy visualization of signal on the brain sections. For brightfield photos of Nisslstained tissue (Figs. 4-8), a compound microscope attached to a CCD camera was used to scan images into the computer.

\section{Nomenclature}

Various nomenclatures have been used to describe budgerigar auditory and vocal brain regions (Paton, et al., 1981; Brauth et al., 1994; Striedter, 1994; Durand et al., 1997). To simplify this problem, we adopted the following policy. For brain regions that have been found in all avian species studied to date, such as stations of the auditory pathway (Karten, 1967, 1968; Bonke et al., 1979; Muller and Scheich, 1985; Brauth et al., 1987; Fortune and Margoliash 1992, 1995; Vates et al., 1996), we used the names by which they are most commonly called. For brain structures that have not been found in all avian orders, such as the forebrain "vocal" nuclei (Nottebohm et al., 1976; Paton et al., 1981; Nottebohm, 1980; Kroodsma and Konishi, 1991; Striedter, 1994; Durand et al., 1997), we followed the approach of Striedter (1994) and used different names for different orders, even if structures appeared to be very similar. We did not separate the paleostriatum augmentatum (PA) from the lobus parolfactorius (LPO) within the paleostriatum as is commonly done, because we could not find a Nissl boundary between the two, particularly in the parasagittal plane. Nomenclature explanations for other brain regions are given in Results.

When making comparisons with the mammalian brain, the avian neostriatum $(\mathrm{N})$ should not be considered to be homologous or analogous to the mammalian neostriatum. The same holds for basalis (Bas). Such nomenclature for birds has been shown to be in error (Karten and Shimizu, 1989; Wild et al., 1993; Medina and Reiner, 1995; Veenman et al., 1995, 1997; Striedter, 1997) and still results in confusion or inaccurate comparisons for a number of neurobiologists who are not aware of the problem (for example, see discussion by Aldridge and Berridge, 1998, for a recent neostriatum comparison). The avian neostriatum is now thought to correspond to a portion or portions of the mammalian cortex (see Striedter, 1997, for a review).

A commonly used name for budgerigars, parakeets, means small parrot and can also create confusion. Phylogenetic (Sibley and Ahlquist, 1990) and mitochondrial DNA (Miyaki et al., 1998) evidence demonstrates that budgerigars fall within the general parrot order. Other small parrots, such as South American parakeets, are more closely related to bigger parrots of the same continent than they are to budgerigars (the Australian parakeet). That is, parakeets do not form a genetic clade separate from parrots (Miyaki et al., 1998), and their common name referring to their body size is a trait resulting from convergence.

\section{RESULTS \\ General considerations}

Striking ZENK mRNA induction was seen in a number of budgerigar brain structures as a result of hearing or vocalizing warble song. Figures 2 and 3 show parasagittal and frontal brain section series, respectively. Comparison of the quiet control with the hearing only group (first and second columns of Figs. 2, 3) allowed an assessment of areas activated by hearing the conspecific auditory stimulus. In turn, comparison of the hearing only with the hearing and vocalizing group (second and third columns of Figs. 2, 3) allowed an assessment of areas activated by vocalizing. The identified brain structures are represented in adjacent camera lucida drawings (fourth column of Figs. 2, 3). Dashed lines indicate boundaries of hearing- or vocalizing-induced ZENK expression. Solid lines indicate cresyl-defined boundaries.

\section{Basal ZENK expression}

ZENK gene expression was very low or undetectable throughout the brains of quiet controls, except for several bands of ZENK-expressing cells rostral and lateral to the caudal-medial telencephalon. These bands comprised portions of both the neostriatum (N) and hyperstriatum ventrale (HV) and can be seen in both the parasagittal (Fig. 2B,D,E) and frontal (Fig. 3M-P) series. ZENK expression in this area was variable. For example, in the hearing only animal shown, this region had higher expression than in the control (Figs. 2A,B, 3N-P), but this was not consistent in the other animals. ZENK expression in this area may be a result of some variable that is not controlled for in our experimental paradigm.

\section{Auditory regulation}

The hearing only group showed increased ZENK gene expression in a large area that encompasses the caudalmedial telencephalon (Figs. 2A-G, 3M-R). This overall area was round, in both the parasagittal and frontal planes, and contained a negative elliptically shaped core; in the animal shown, this pattern is particularly clear in Figures 2C,D and 3N-Q. Each major subdivision of the caudal-medial telencephalon-the hyperstriatum, neostriatum, archistriatum, and paleostriatum-had at least one region that contributed to this overall area of auditory-induced ZENK expression.

$\boldsymbol{C M H V}$. Within HV, hearing-induced ZENK expression was seen in a caudomedial region directly overlying an equally positive portion of the neostriatum (Figs. $2 \mathrm{~A}-\mathrm{E}$, 

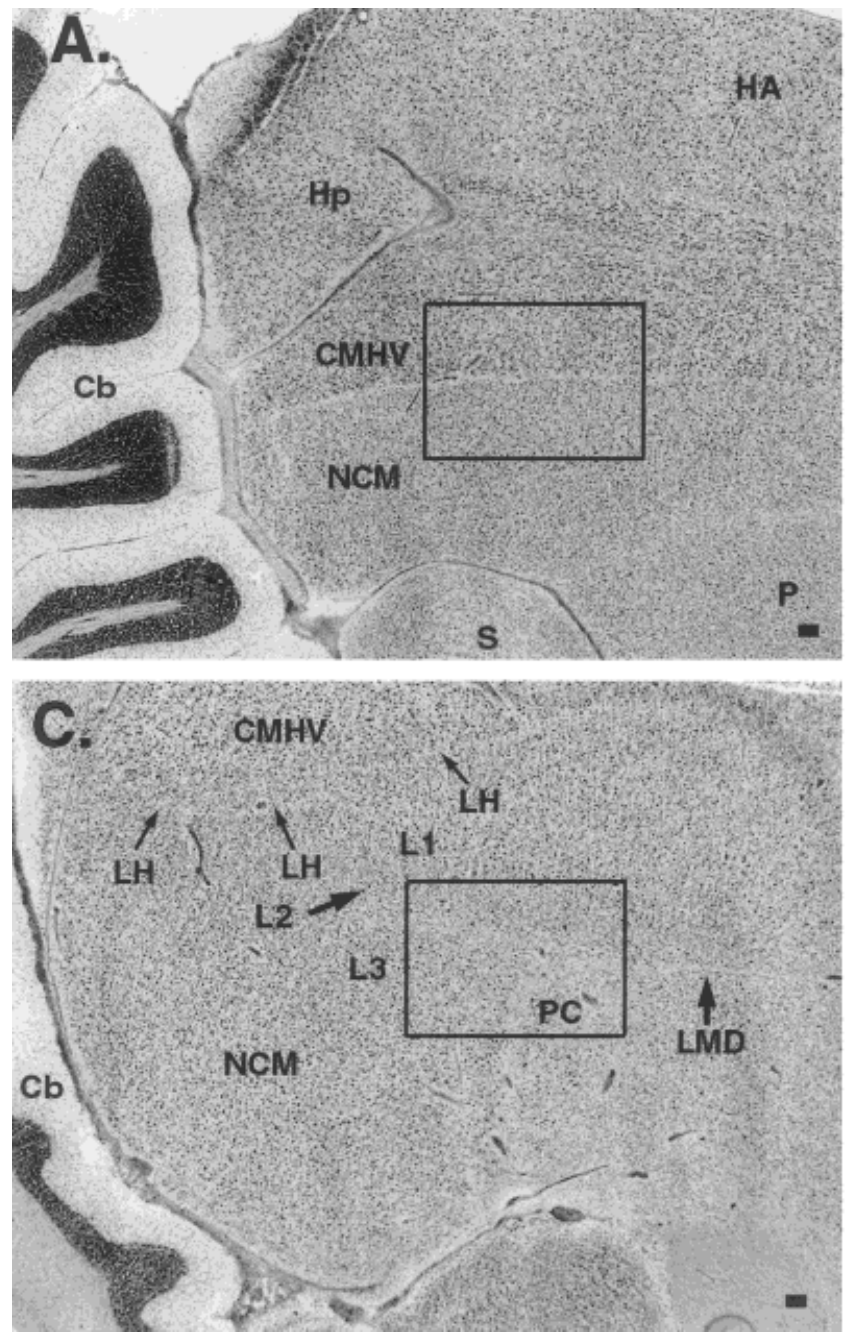

Fig. 4. Nissl definition of brain areas in the caudomedial telencephalon that showed hearing-induced ZENK expression. A: Lowmagnification view of a corresponding parasagittal section adjacent to that shown in Figure 2A. B: High-magnification view of the boxed area in A. C: Low-magnification view of a corresponding parasagittal section adjacent to that shown in Figure 2C. D: High-magnification view of the boxed area in C. Arrows point to Nissl-defined boundaries.

$3 \mathrm{M}-\mathrm{Q})$. Although one cannot see a separation in the ZENK expression pattern between $\mathrm{HV}$ and the neostriatum (Fig. 2A), a distinct boundary formed by the lamina hyperstriatica (LH) is clearly seen with Nissl staining (Fig. 4A,B). As best appreciated in the frontal series, this region of $\mathrm{HV}$ expression begins close to the midline and extends laterally until it becomes continuous with the area of ZENK-expressing cells present in quiet controls (Fig. 3M-P). Seen parasagittally, the region extends until HV's very caudal end (Fig. 2A-E). In the songbird brain, a similarly located area of caudal-medial HV (CMHV) has been described as showing hearing-induced ZENK gene expression (Mello et al., 1992; Mello and Clayton, 1994). This region was shown to be continuous with an auditory lateral part, CLHV, by connectivity (Vates et al., 1996), that also shows hearing-induced gene expression (Jarvis
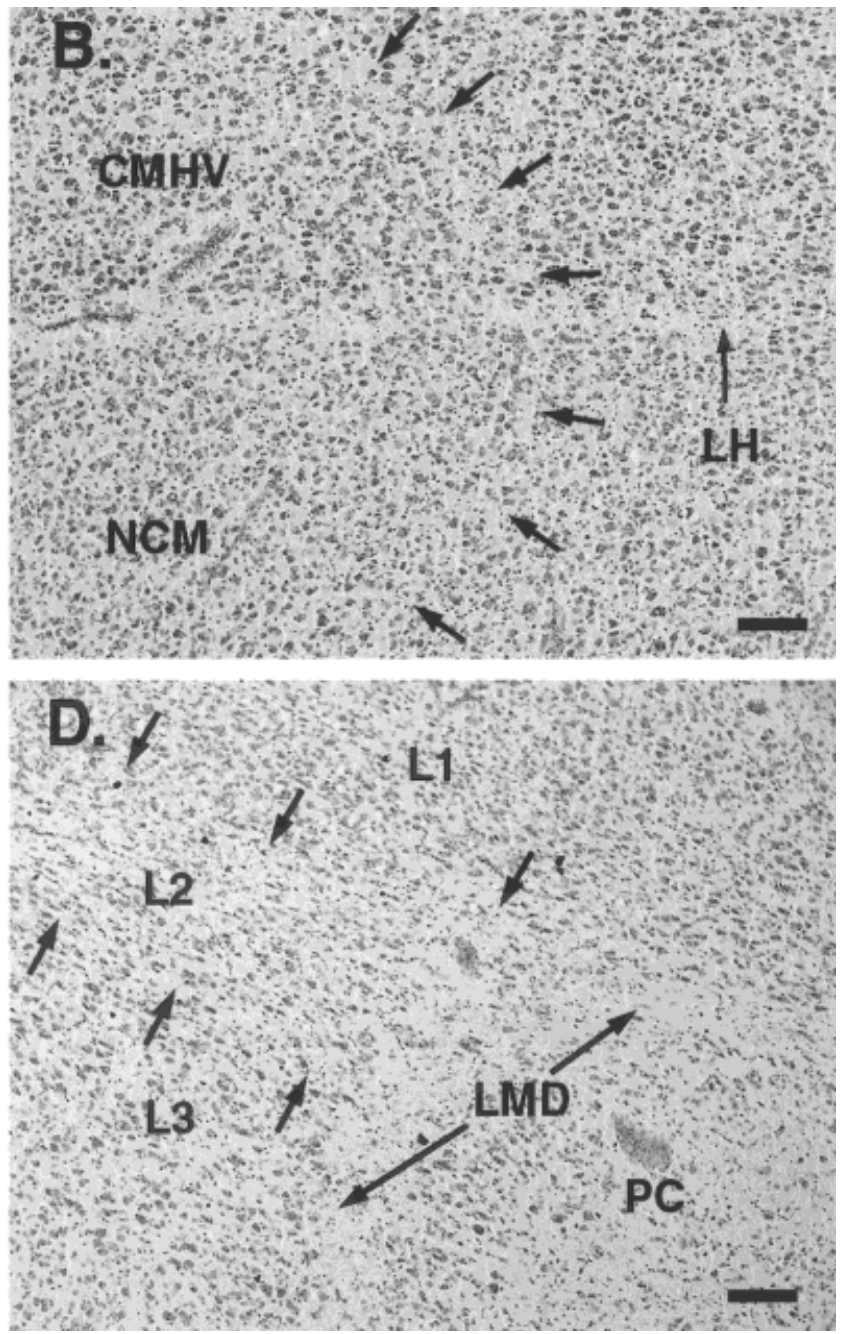

The strip of low cellular density that crosses the LH border from CMHV to NCM in B is coincident with the rostral boundary of hearing-induced ZENK gene expression in Figure 2A; the boundaries of field L2 in D are coincident with the boundaries of the central negative core for ZENK expression in Figure 2C. Orientation: dorsal is up and anterior to the right. S, septum; other abbreviations are defined in the list. Scale bars $=100 \mu \mathrm{m}$.

and Nottebohm, 1997). We believe the HV region described here in the budgerigar brain to be the homologous counterpart of that described in songbirds. With budgerigars, we could not distinguish medial and lateral halves; there was no separation in the gene expression (Fig. $3 \mathrm{M}-\mathrm{Q}$ ) or Nissl patterns. We thus designate the entire HV region described here as budgerigar CMHV.

NCM, field L, and other neostriatal fields. Within $\mathrm{N}$, hearing-induced ZENK expression paralleled that of the overlying CMHV, with the exception that the induced $\mathrm{N}$ area was larger and extended more laterally than CMHV (Figs. 2A-G, 3M-R). Nissl staining shows a rostral boundary of somewhat lower cell density that is continuous with a similar band of cells in the overlying CMHV. This Nissl boundary corresponds to the hearing-induced gene expression boundary (arrows in Fig. 4B). Consistent 
absence of induction was found in an elliptical central portion of caudal $\mathrm{N}$, whose shape and location identified it as field L2 (Figs. 2A-D, 3M-P; Muller and Scheich, 1985; Brauth and McHale, 1988). Nissl staining shows L2 as a strip of cells smaller than the surrounding $\mathrm{N}$, angled away from the caudodorsal end of the paleostriatum (Fig. 4C,D). With Nissl staining, medial portions of L2 were more prominent in the frontal than in the sagittal plane (not shown). In songbirds, a similar pattern of hearing-induced ZENK expression was found in the caudal neostriatum adjacent to CMHV, whose medial portion is called NCM, the caudomedial neostriatum (Mello et al., 1992), and whose lateral portion is continuous with fields L1 and L3 which also show hearing-induced ZENK expression, surrounding a negative L2 (Mello and Clayton, 1994; Vates et al., 1996). For budgerigars, we could not distinguish Nissl boundaries between the different neostriatal fields outside of L2. Thus, we designate the entire region that showed hearing-induced expression described here as budgerigar NCM, which surrounds the presumed fields L1 and L3 (Fig. 2A-D).

A smaller patchy area of less robust hearing-induced expression occurred more laterally in budgerigar dorsal N. Expression is seen as a dorsoventral column with a small negative region along the same diagonal as field L2 (Fig. $3 \mathrm{M}, \mathrm{N})$. The dorsal part of this region appears to be partly coincident with the area described as the neostriatum intermedium pars dorsolateralis (NIDL) in budgerigars (Brauth and McHale, 1988). It also appears to be contained within the broader region corresponding to the dorsocaudal neostriatum (Ndc) in chicken (Metzger et al., 1998) or the dorsal neostriatum (Nd) in pigeon (Wild et al., 1993), which receives auditory inputs from fields L1 and L3. In songbirds, $\mathrm{Nd}$ is thought to correspond to the shelf region located underneath the song control nucleus HVC (high vocal center; Wild, 1994; Vates et al., 1996; Mello et al., 1998); the shelf in songbirds shows marked ZENK induction in response to hearing conspecific song (Mello and Clayton, 1994; Jarvis and Nottebohm, 1997).

$\boldsymbol{P C}$. Hearing-induced expression was also observed in a small region of the caudal paleostriatum $(\mathrm{P})$ underlying the caudal neostriatum. In the parasagittal series, this region is first seen rostroventral to the field $\mathrm{L}$ complex (Figs. 2C,D, 4C,D). Farther laterally (Fig. 2E) it separates from the part of neostriatum that shows hearing-induced expression and is adjacent to a negative paleostriatum primitivum $(\mathrm{PP})$. In frontal sections, the entire caudal $\mathrm{P}$ is seen as a round area directly ventral to the negative field L2 and positive neostriatum that shows hearing-induced expression (Figs. 3M). In songbirds, a similar region called caudal paleostriatum (PC) that lies ventral to field L2 shows hearing-induced expression (Mello and Clayton, 1994; Mello and Ribeiro, 1998); this region is thought to receive an auditory projection from the thalamus (Kelley and Nottebohm, 1979; Vates et al., 1996; called paleostriatum augmentatum [PA] in those studies). We therefore designate this region of the budgerigar brain as $P C$ (Figs. $2 \mathrm{C}-2 \mathrm{E}, 3 \mathrm{M})$.

$\boldsymbol{A C M}$. In the hearing only group, we observed ZENK expression within caudal portions of the caudomedial archistriatum ventral and lateral to PC (Figs. 3M, 5B-E). This expression was not as pronounced as that seen in other regions and was not localized to a particular nucleus. However, we noted that its location relative to $\mathrm{PC}$ is similar to that of an archistriatal region in the pigeon brain called Aivm, the ventral medial nucleus of the intermediate archistriatum. Aivm is connected with auditory areas and appears to be part of a descending projection within the central auditory pathways of pigeons (Wild et al., 1993; note that PC was called PA in that study). Because we could not distinguish Nissl boundaries that defined the hearing-induced region of gene expression described here in budgerigars, we decided to define it generally as the caudomedial archistriatum (ACM), because it includes the most caudal and medial aspect of the budgerigar archistriatum. In pigeons, Aivm is thought to correspond to the RA cup region located around the song control nucleus RA (robust nucleus of the archistriatum; Wild, 1994; Mello et al., 1998); the RA cup in songbirds shows ZENK induction in response to hearing song (Mello and Clayton, 1994; Jarvis et al., 1998). The remaining budgerigar archistriatum in the hearing only animals showed very little or undetectable ZENK expression (Fig. 2D-F, 3G-N), including a region in the anterior archistriatum, called $R A m$, nucleus archistriatalis rostromedialis (Fig. 3J), which receives a projection from the caudal neostriatum (Brauth and McHale, 1988).

MLd. Within the midbrain (M), a region ventral to the tectal ventricle showed hearing-induced ZENK gene expression; the effect was more pronounced in the vocalizing animal shown (Figs. 2C,D, 3M,N). With cresyl staining, this region is easily identified as the dorsal part of the lateral mesencephalic nucleus, MLd (Fig. 5A). MLd labeling was not uniform, but patchy, and the exact pattern varied from one section to the next. However, wherever there was expression, it was confined within MLd's borders. MLd is the main auditory nucleus of the avian midbrain (Karten, 1968) and also shows hearing-induced ZENK expression in songbirds (Mello and Clayton, 1994).

Other brain regions. We did not detect hearinginduced ZENK expression in areas of the frontal telencephalon that are thought to constitute a rostral auditory pathway in budgerigars (Hall et al., 1993; Striedter, 1994; Durand et al., 1997; Farabaugh and Wild, 1997; Wild et al., 1997a). These are: 1) nucleus basalis (Bas; Figs. 2E,F, $3 \mathrm{E}-\mathrm{G}), 2$ ) the lateral frontal neostriatum (Figs. 2D-F 3EG), and 3) areas surrounding vocal nuclei such as the supracentral nucleus of the lateral neostriatum (NLs) and the ventral nucleus of the lateral neostriatum (Nlv; Figs. $2 \mathrm{G}, 3 \mathrm{I}, \mathrm{J})$. Hearing-induced expression was also not found in the thalamic auditory station, nucleus ovoidalis $(\mathrm{Ov}$; Figs. 2B, 3L, 5B,D). Paucity of ZENK expression was also seen in Bas and Ov of songbirds (Mello and Clayton, 1994; Mello and Ribeiro, 1998). There was some expression, however, in a shell of cells around Ov (Fig. 5D), which has also been seen in songbirds (Jarvis and Mello, unpublished results). The Ov shell is also connected with the auditory pathway (Durand et al., 1992; Vates et al., 1996; Mello et al., 1998).

\section{Vocal regulation}

Animals who vocalized (warbled) showed, in addition to the hearing-activated regions described above, high induced ZENK gene expression in nine brain structures: seven in the anterior telencephalon, one in the thalamus, and one in the midbrain (Figs. 2A-G, 3C-J). As with the hearing-induced expression pattern, each major telencephalic subdivision-hyperstriatum, neostriatum, archistriatum, and paleostriatum-had one or more regions 

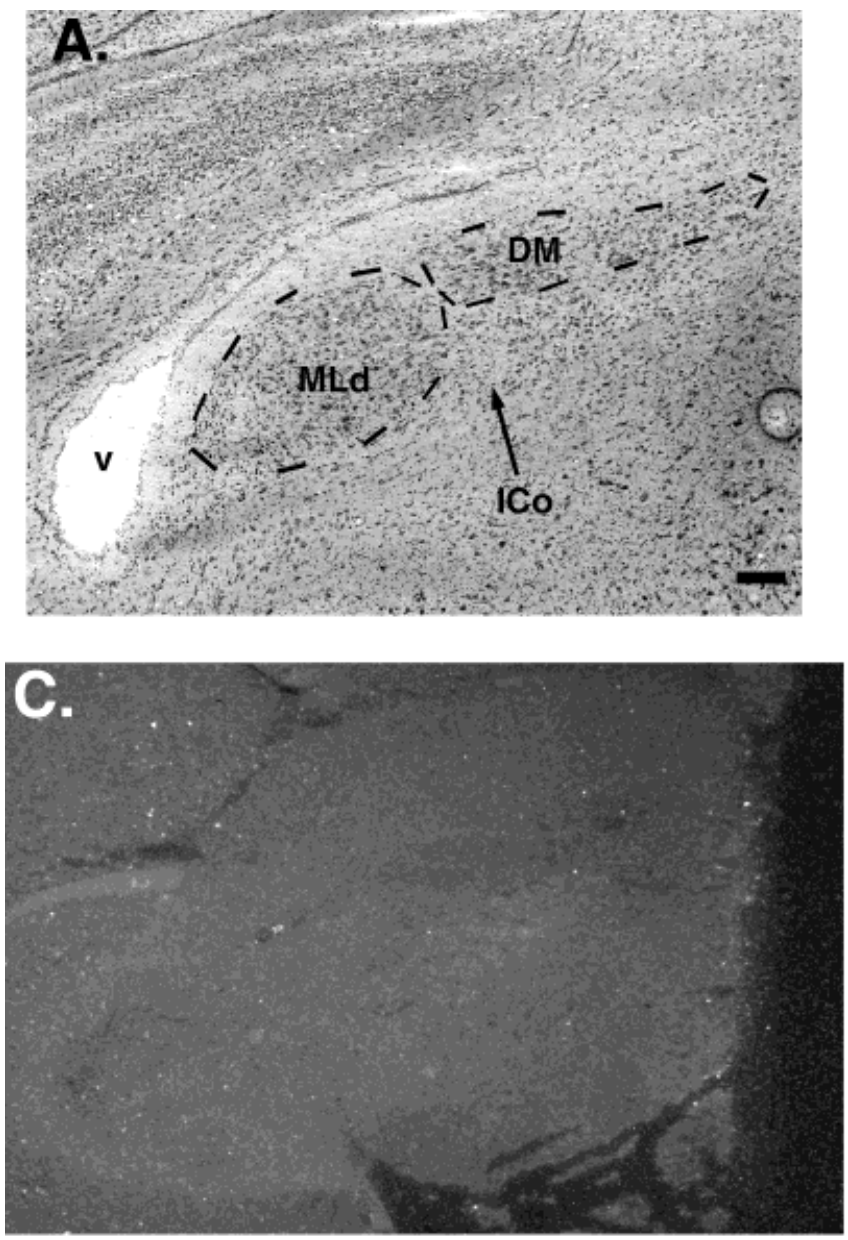

Fig. 5. A,B: Nissl definition of auditory and vocal regions in the midbrain, thalamus, and caudomedial archistriatum (ACM) of frontal sections adjacent to those shown in Figures $3 \mathrm{M}$ and L, respectively. The dashed lines indicate the Nissl boundaries of MLd and DM of ICo, and DMm. The section in B is cut through the caudal pole of Ov. C-E: Darkfield views of frontal brain sections hybridized to a radioactively labeled canary ZENK riboprobe of the area represented in B, from a quiet control (C), hearing only (D), and hearing and vocalizing (E) animal. Low hearing-induced expression occurred in ACM and a shell of cells around Ov (D); low vocally induced expression occurred in the dorsal thalamus surrounding DMm (E). v, Tectal ventricle; other abbreviations are defined in the list. Orientation: dorsal is up and medial to the right. Scale bars $=100 \mu \mathrm{m}$.

that contributed to the vocally regulated ZENK gene expression. Overall, the expression pattern can be grouped into three clusters: 1) three nuclei located anteriormedially (Figs. 2A-D, 3C-I), 2) two nuclei located anterior-laterally overlying Bas (Figs. 2E,F, 3E,F), and 3) two nuclei also located laterally but more posterior to the others (Figs. 2G, 3H-J).

HVo complex. Within the anterior-medial cluster, vocally induced ZENK expression in HV extended from near
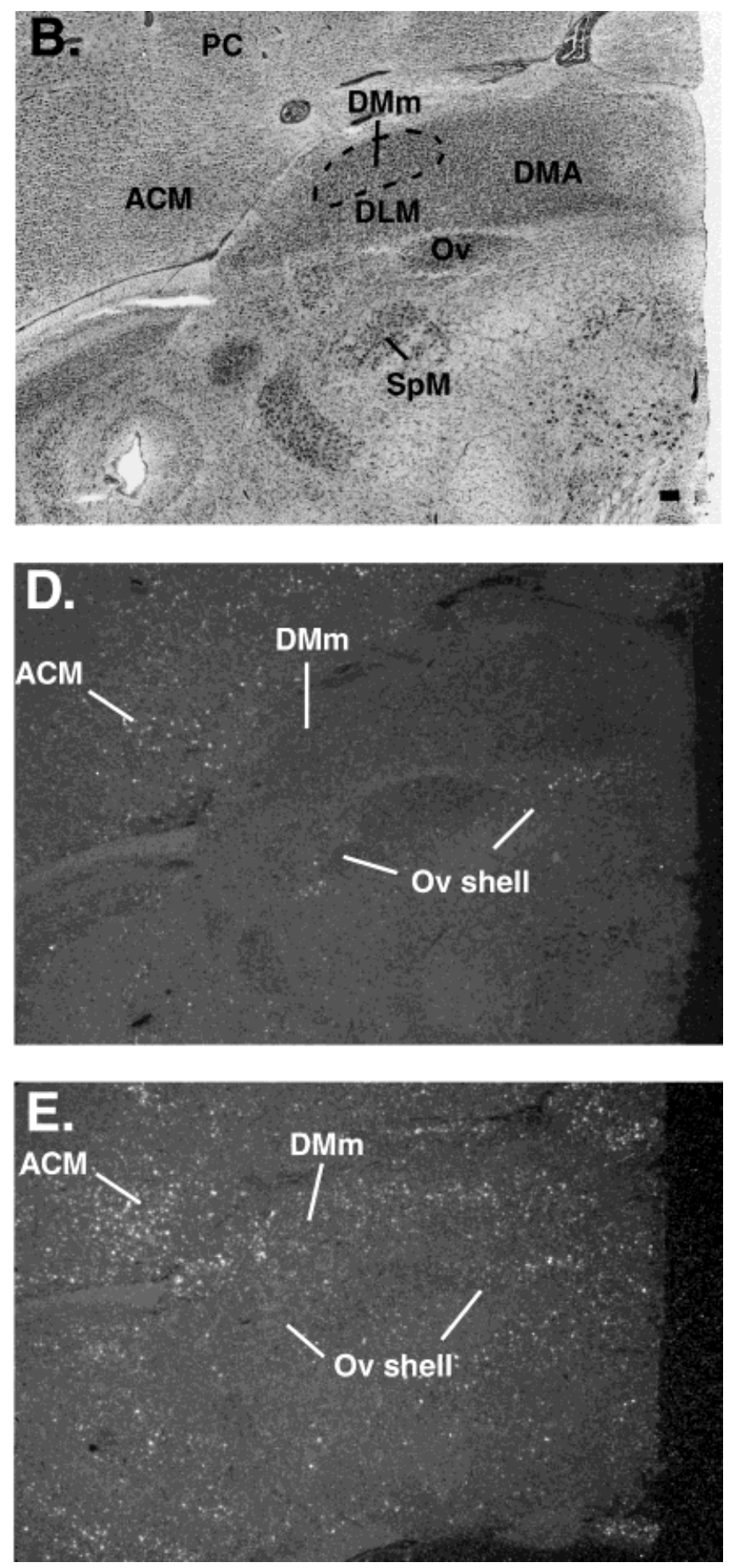

the wall of the lateral ventricle along the midline to about midway into the telencephalon (Figs. 2A-C, 3C-E). In parasagittal series this area of ZENK expression in $\mathrm{HV}$ is oblong and borders its dorsal and ventral laminae, respectively, LF and LH (Fig. 2A-C). In the frontal plane, the region is oval rostrally (Fig $3 \mathrm{C}$ ), elongates medially at its most central portion (Fig. 3D), and becomes smaller again caudally (Fig. 3E). Cytoarchitectonically a semicircular nucleus can be distinguished by larger cell bodies located 


\section{A. Sagittal}
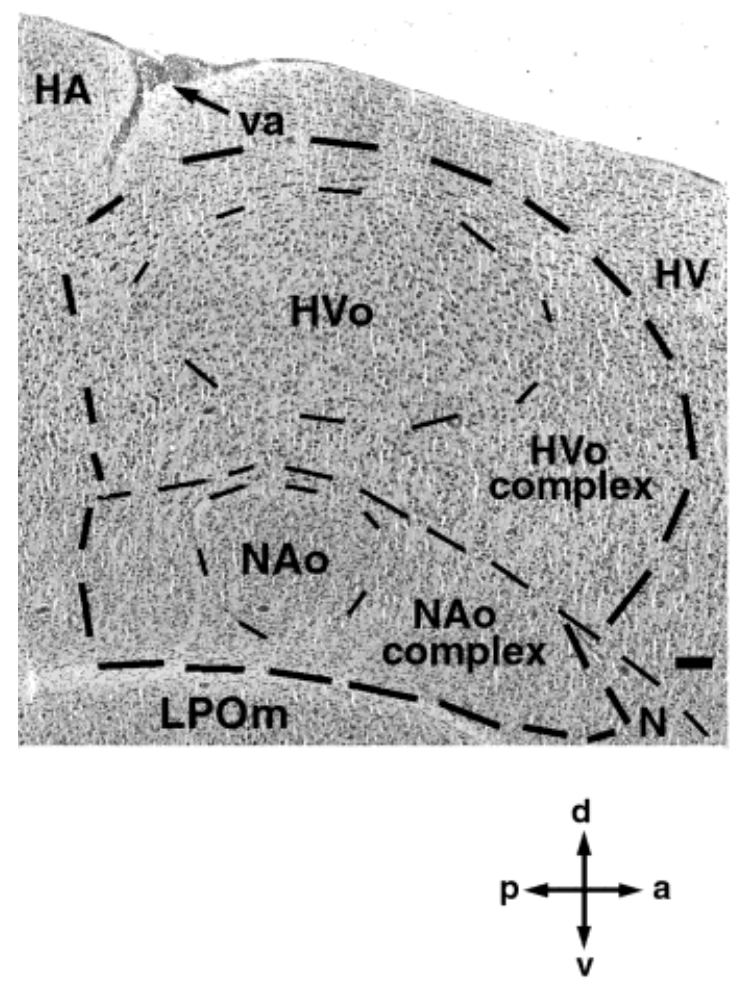

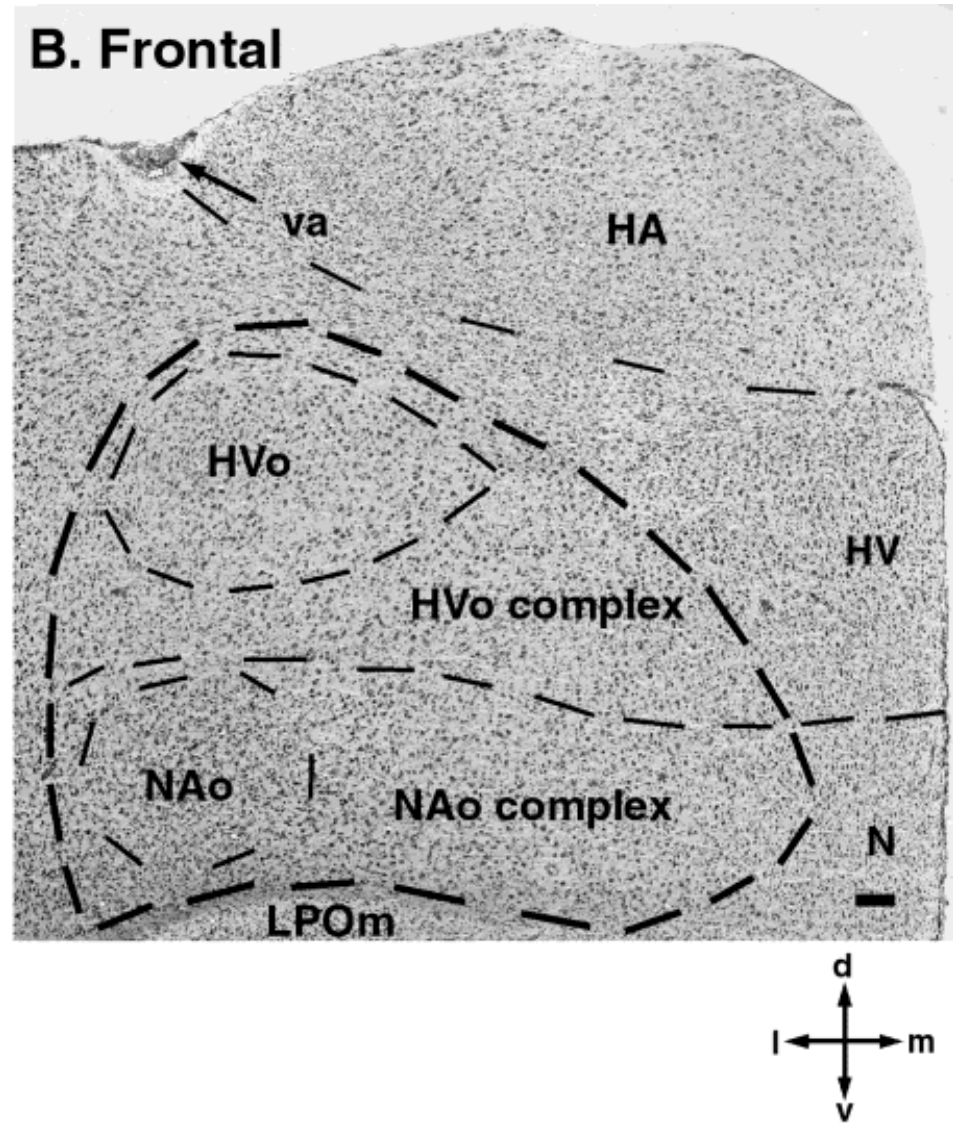

Fig. 6. Nissl definition of brain regions that show vocally induced ZENK expression in the anterior-medial telencephalic cluster. A: Detailed parasagittal view of the NAo and HVo complexes corresponding to the level shown in Figure 2C. B: Detailed frontal view of the NAo and HVo complexes corresponding to the level shown in Figure $3 \mathrm{E}$. Thin dashed lines indicate nuclear boundaries defined by Nissl staining; thicker dashed lines define the regions of vocally induced ZENK gene expression. C: Parasagittal view of LPOm at the

laterally within the larger area of vocally induced gene activation (cf. Fig. 6A,B to Figs. 2C, 3E, respectively). This lateral nucleus corresponds to what has been previously described as $H V o$, the oval nucleus of the ventral hyperstriatum, and is connected to other nuclei of the vocal pathway (Striedter, 1994; Durand et al., 1997). Thus, we decided to designate the entire ZENK-activated region as the HVo complex (HVoc). The location of the HVoc can be reliably found underneath an indentation in the surface of the brain (called the valecula) containing a large blood vessel (Fig. 6A,B).

NAo complex. The second region of the anteriormedial cluster that showed vocally regulated gene expression was found within the neostriatum directly underlying HVoc, with a shape paralleling that of HVoc (Figs. 2A-C, 3C-E). Similar to the HVoc, a round nucleus, comprising of small, tightly packed cells, can be distinguished laterally within the larger area of neostriatum showing vocally activated gene expression (cf. Fig. 6A,B to Figs. 2C, 3E, respectively). This round nucleus corresponds to what has been previously described as NAo, the oval nucleus of the level shown in Figure 2C. D,E: High-magnification views of the left and right boxed areas in C, respectively. The Nissl-defined boundary of LPOm (E) and its extensions (D) is coincident with the gene expression boundary; there is a predominance of larger cells throughout LPOm and in the extensions than in the surrounding paleostriatum. Orientation: dorsal is up for all panels, anterior to the right for $\mathrm{A}$ and $\mathrm{C}$, and medial to the left for B. va, Venacula. Scale bars $=100 \mu \mathrm{m}$. anterior neostriatum (Striedter, 1994). Regions medially and ventrally adjacent to NAo have been described as NAom (medial region adjacent to NAo) and NAs (the subcentral nucleus of the anterior neostriatum, ventromedial to Nao; Paton et al., 1981; Durand et al., 1997). We could not distinguish these subdivisions by the gene expression pattern. Thus, we decided to designate the entire region defined by gene activation as the NAo complex (NAoc), encompassing NAom, NAs, and NAo (Fig. 6A,B). The combined shapes of the HVo and NAo complexes form a continuous region of expression that is relatively flat were they meet at LH, but curved otherwise (Figs. 2A-C, 3CE).

LPOm. The third nucleus of the anterior-medial cluster and the largest that showed vocally induced gene expression was located within the anterior paleostriatum underlying the HVo and NAo complexes (Figs. 2A-D, 3DI). This structure was quite complex, taking on various shapes and dimensions along its rostrocaudal and mediolateral axes. In the parasagittal series, one observes a circular structure in medial sections situated near 


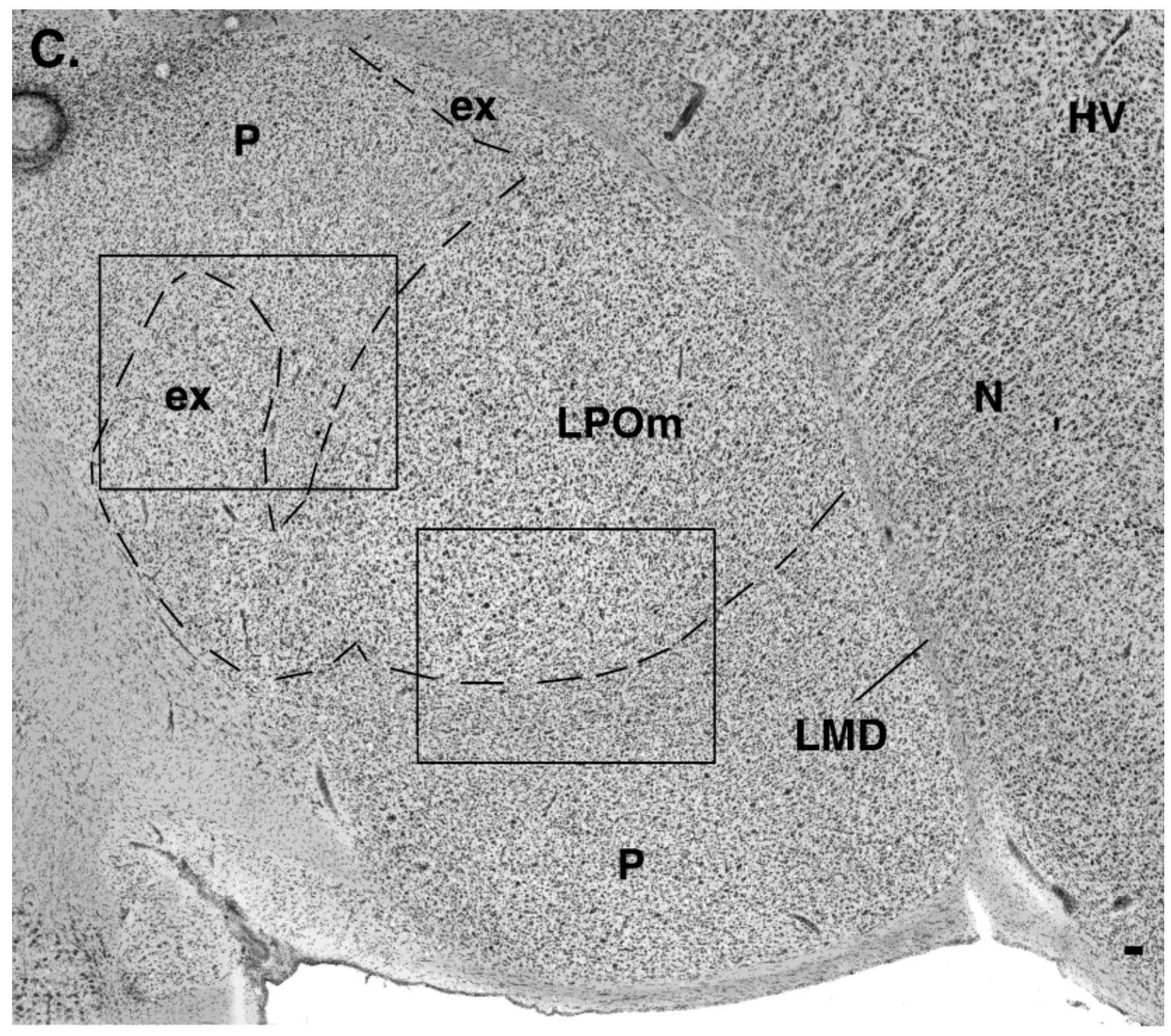

b

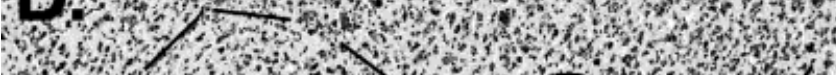

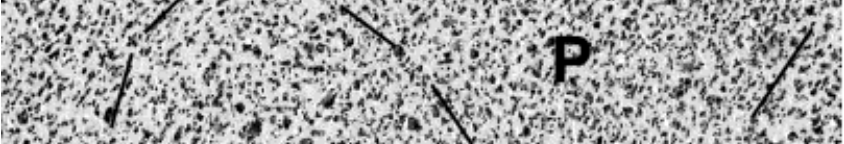

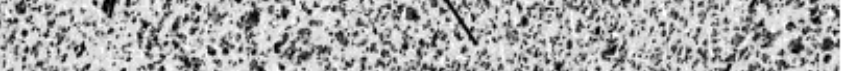

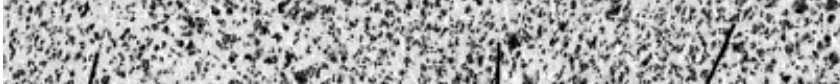

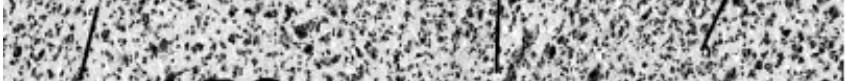

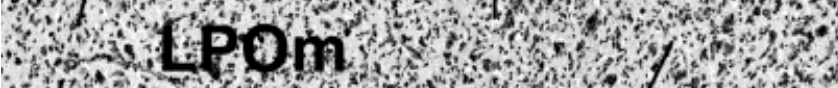

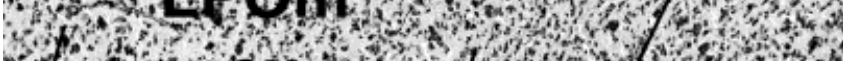

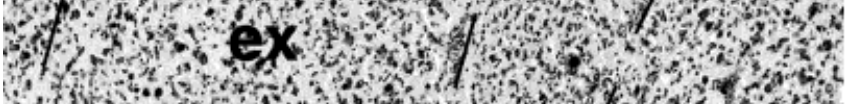

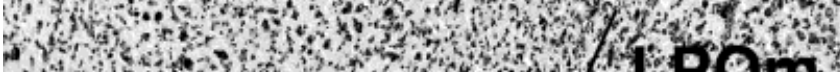

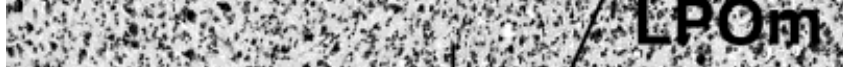

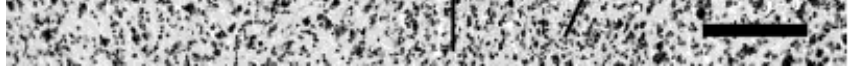

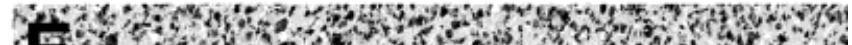

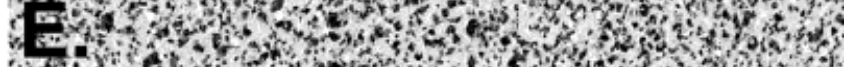

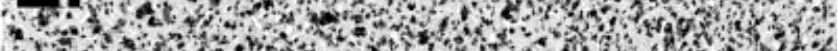

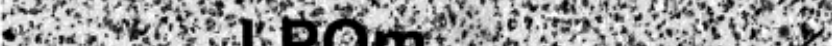

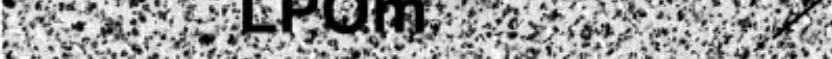

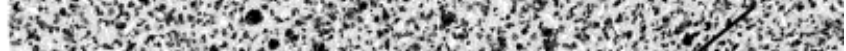

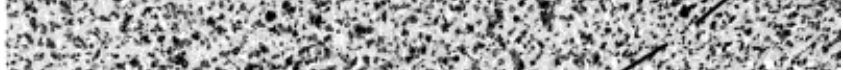

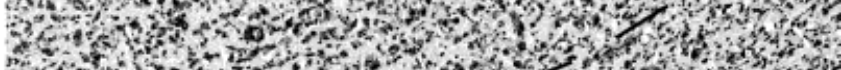

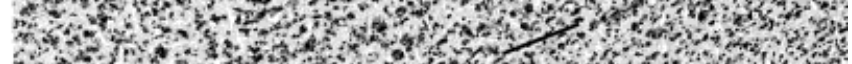

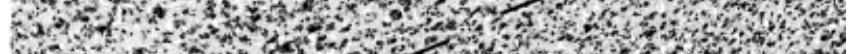

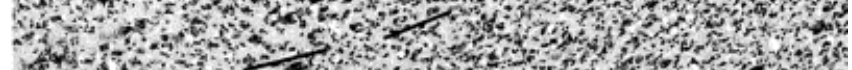

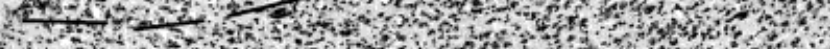

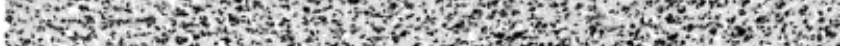

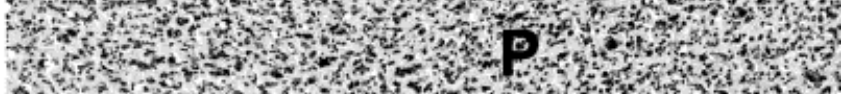
S. ${ }^{2}$.

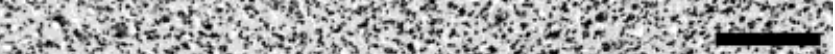

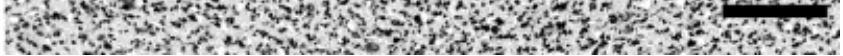


dorsal P (Fig. 2A). Also present is a thin layer of labeled cells abutting the rostral-dorsal $\mathrm{P}$ boundary defined by the LMD (Fig. 2A). Farther laterally, the large round area is positioned more dorsally against LMD adjacent to NAo (Fig. 2B). Two small caudal areas of weaker gene activation appear, one still dorsally opposed to LMD and the other more ventral (Fig. 2B). These two caudal areas merge with the large core area of ZENK induction more laterally, forming hook-like extensions to it (designated "ex" in Fig. 2C). Still farther laterally, the main body of ZENK expression separates from the extensions (Fig. 2D). In the frontal series, expression is seen rostrally as a small group of round structures, several of which are opposed to LMD (Fig. 3D). More caudally, a continuous region of ZENK expression is seen that elongates along an angled medial-lateral axis, with the medial portion less round and more ventral than the lateral one (Fig. 3E). Farther caudally, the activated region becomes rounder again (Fig. 3F), with the dorsal extension abutting LMD (Fig. 3G). Even more caudally, only the dorsal and ventral extensions can be seen (Fig. 3H,I). Cytoarchitectonically, the regions containing vocally induced ZENK expression, including the extensions, had a higher proportion of larger cells than the surrounding $\mathrm{P}$ (Fig. 6C-E). There were no obvious boundaries between these different domains (Fig. 6C-E). However, the boundaries of medial LPOm defined by Nissl staining were more prominent in the sagittal plane (not shown) than in the frontal. A large semicircular nucleus within budgerigar lateral paleostriatum has been described as LPOm, the magnocellular nucleus of the lobus parolfactorius (Striedter, 1994). The reported shape of LPOm (Striedter, 1994; Durand et al., 1997) conforms to part of the vocally induced gene expression region described here, as seen in Figure 3F. Because we could not find any Nissl boundaries between the previously described LPOm and the gene expression domain described here, we now designate the much larger structure described here, with its hook-like extensions, as $\mathrm{LPOm}$ (Figs. 2, 3, 6C-E).

$\boldsymbol{I A N}$ and $\boldsymbol{I A H V}$. The anterior-lateral cluster of vocally driven gene expression includes two structures that abut the lateral surface of the brain, which in frontal sections fall within some of the same planes as the anterior-medial cluster (Fig. 3E,F). In parasagittal sections, a circular region of expression is first seen in the anterior part of lateral $\mathrm{HV}$ dorsal to Bas (Fig. 2E). At this level, anterior $\mathrm{HV}$ is separated from posterior HV by N. More laterally, as the anterior part of $\mathrm{HV}$ becomes smaller, the domain of ZENK activation within anterior HV becomes continuous with a region of induction within the neostriatum directly ventral to it (Fig. 2F). This neostriatal region is elongated in the dorsoventral direction and overlies Bas (Fig. 2F). In frontal sections, the ventral tip of the neostriatal region appears round and directly overlies Bas (Fig. 3F). More rostrally, it becomes continuous dorsally with the $\mathrm{HV}$ area of induced expression overlying it (Fig. 3E). Although one cannot see a clear separation between the $\mathrm{HV}$ and $\mathrm{N}$ based on the ZENK expression pattern, the boundary formed by LH is clearly seen in Nissl staining in parasagittal plane (Fig. 7A,B), but the boundary is not clear in frontal sections (Fig. 7C-D). In both $\mathrm{HV}$ and $\mathrm{N}$, the expression pattern closely matches Nissl-defined nuclei whose cells appear larger than those of the surrounding tissue; this effect is more prominent in the parasagittal plane (Fig. 7A,B). Together, the HV and $\mathrm{N}$ domains form a continuous cone-shaped structure with an orientation perpendicular to the dorsal surface of the anterior telencephalon. A loosely defined area called the lateral frontal $\mathrm{N}(\mathrm{NFl})$ and adjacent $\mathrm{HV}$ region has been described as having connectivity with vocal and auditory nuclei in the budgerigar brain (Hall et al., 1993; Striedter, 1994; Durand et al., 1997; Farabaugh and Wild, 1997). However, well-defined nuclei as presented here have not been described. We thus designate them as the lateral nucleus of the anterior neostriatum (lAN) and lateral nucleus of the anterior hyperstriatum ventrale (1AHV; Figs. 2E,F, 3E,F, 7A-D). We use the term "anterior" in their naming instead of "frontal" to reflect a more congruent nomenclature with the anteriormedial cluster (HVoc, NAoc, and LPOm), because they are in the same frontal-anterior plane (Fig. 3E,F)

NLc. The posterior-lateral cluster of vocally driven gene expression is situated posterior to the other clusters and contains one region within the lateral neostriatum and one within the lateral archistriatum. The lateral neostriatal region is vertically oriented, is oval, and borders the lateral surface of the brain (Figs. 2G, 3H-J). In frontal sections, it is seen as a lateral protrusion at the lateral surface of the brain (Fig. 3H-J). In parasagittal sections, it is seen in the anterior part of the lateralmost sections and appears to have rounded dorsal and ventral subdivisions (Fig. 2G). The cytoarchitectonic distinction of this region is relatively apparent in frontal sections; its cells are oriented in a dorsoventral curvature (Fig. 8) that matches the gene expression boundary (Fig. 3J). A nucleus with similar boundaries and cellular morphology has been well characterized as part of the budgerigar vocal pathway (Paton et al., 1981; Striedter, 1994; Durand et al., 1997) and is called NLc, the central nucleus of the lateral neostriatum (Striedter, 1994).

$\boldsymbol{A A C}$. The lateral archistriatal structure that showed vocally induced expression is best seen in frontal sections (Fig. 3J). This region is located medially to the caudal part of NLc and abuts the lateral archistriatal boundary defined by the lamina archistriatalis dorsalis (LAD; Fig. 3J). A parasagittal plane containing this region is not shown here, but an asterisk placed in a more medial section indicates its relative position (Fig. $2 \mathrm{~F}$ ). As defined in frontal sections, this structure closely corresponds to AAc, the central nucleus of the anterior archistriatum, another well-characterized nucleus within the budgerigar vocal pathway (Paton et al., 1981; Striedter, 1994; Durand et al., 1997). AAc has been subdivided into dorsal (AAcd) and ventral (AAcv) parts (Durand et al., 1997). We noted these subdivisions in Nissl staining (Fig. 8) but were not able to discern them separately by the gene expression pattern. As was previously reported (Striedter, 1994; Durand et al., 1997), the cells in AAc appear larger than in the surrounding tissue; we also noted that the archistriatal region rostral to AAc also has larger cells but no vocally induced gene activation (not shown).

Dorsal thalamus. Expression in the thalamus in general was less pronounced than in other brain subdivisions (Figs. 2, 3). Nevertheless, we closely examined a region known to be interconnected with telencephalic vocal nuclei (Paton et al., 1981; Striedter, 1994; Durand et al., 1997), which has been named DMm, the magnocellular nucleus of the dorsomedial thalamus (Striedter, 1994). As described by Striedter (1994), DMm was identified in frontal sections as a region in the dorsal thalamus containing larger cells than the surrounding tissue (Fig. 5B). In the 

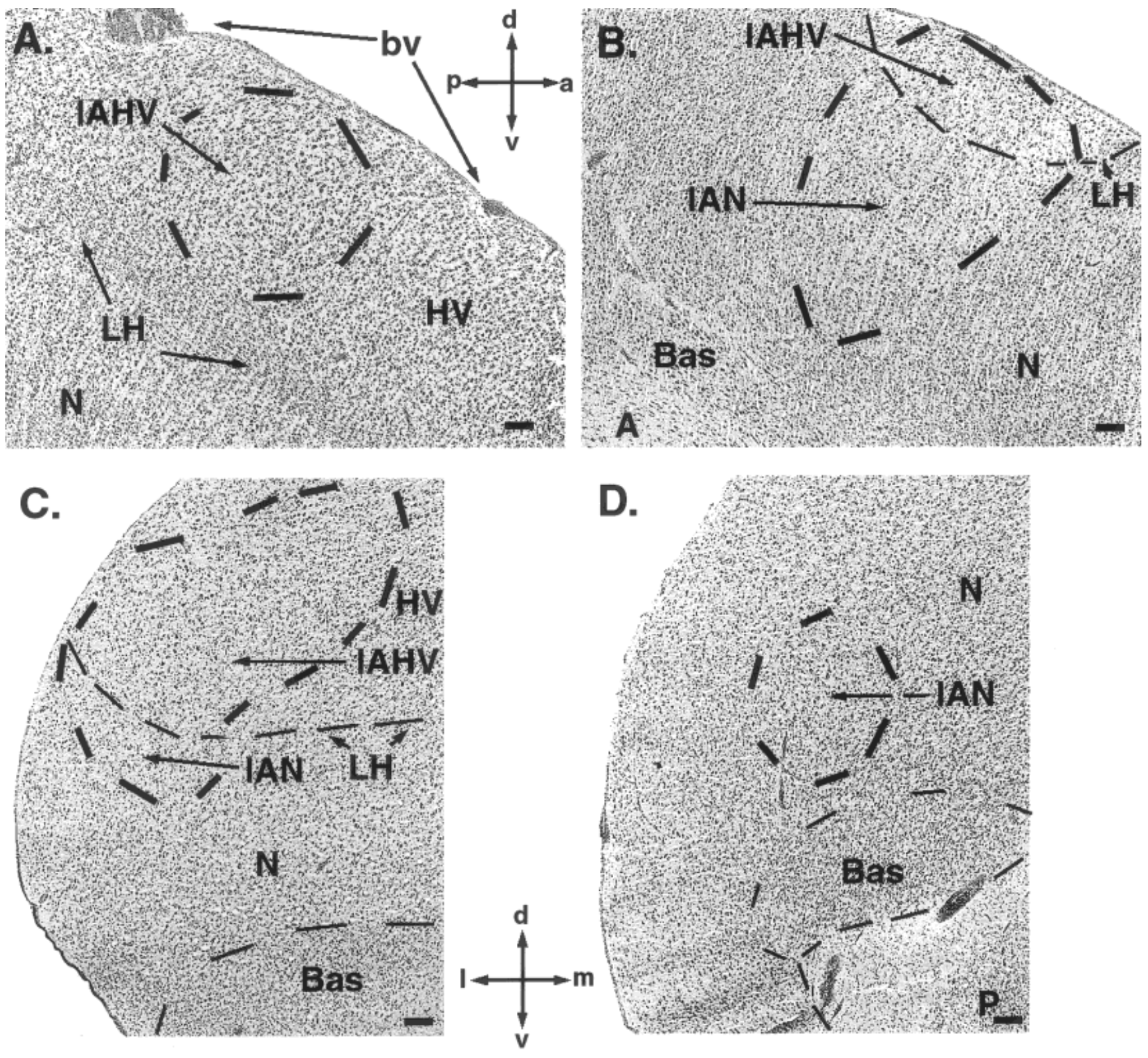

Fig. 7. Nissl definition of brain regions that show vocally induced ZENK expression in the anterior-lateral telencephalic cluster, IAHV and lAN. A,B: Parasagittal views corresponding to Figures $2 \mathrm{E}$ and $2 \mathrm{~F}$, respectively. C,D: Frontal views corresponding to Figures $3 \mathrm{E}$ and $3 \mathrm{~F}$, respectively. Thin dashed lines indicate boundaries defined by Nissl staining alone; thicker dashed lines define the regions of vocally induced ZENK gene expression, which for IAHV and lAN closely

hearing only animals, no detectable expression was seen in DMm or the surrounding dorsal thalamus (Fig. 5C). In the animals who vocalized, a small increase in ZENK expression was seen in DMm as well as areas medial and lateral to DMm (Fig. 5D). More posteriorly, expression appeared only in the lateral part of the dorsal thalamus that may correspond to DLP, the dorsolateral nucleus of the posterior thalamus (not shown). We decided not to expand the definition of the DMm region of expression, as matched Nissl boundaries. However, the Nissl-defined boundaries were more prominent in the sagittal $(A, B)$ than in the frontal $(C, D)$ plane. This is probably due to asymmetric cellular morphology. One can also see a dorsal-ventral columnar or palisade arrangement of cells in the sagittal plane, particularly in the neostriatum, N, dorsal to Bas (A,B). Orientation: dorsal is up for all panels, anterior to the right for $\mathrm{A}$ and $\mathrm{B}$, and medial to the right for $\mathrm{C}$ and D. Scale bars $=100 \mu \mathrm{m}$.

we did for HVoc, NAoc, and LPOm, because the exact identity of nuclei in this region can be difficult to define.

DM. One non-telencephalic structure located anteriormedial to MLd within the intercollicular complex (ICo) of the midbrain also showed vocally induced ZENK expression (Figs. 2C,D, 3M, 5A). Such a region has been described in many avian species as the dorsomedial nucleus (DM) of the ICo (Paton et al., 1981; Wild, 1993; Vicario 1993; Puelles et al., 1994; Reinke and Wild, 1998). In both 


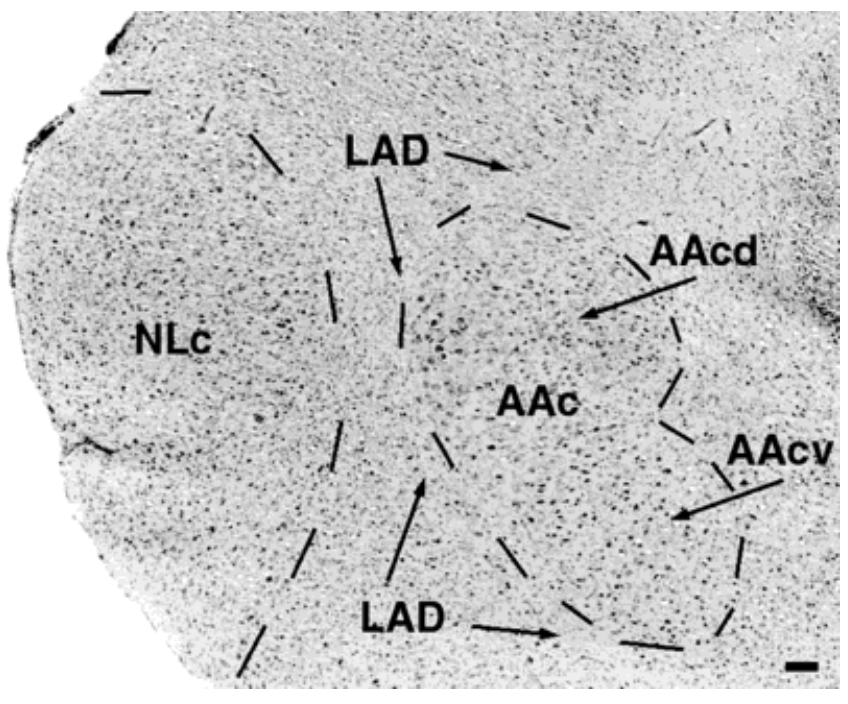

Fig. 8. Nissl definition of brain regions that show vocally induced ZENK expression in the posterior-lateral telencephalic cluster, NLc and AAc, corresponding to sections adjacent to that in Figure 3J. Orientation: dorsal is up and medial is to the right. Scale bar $=100$ $\mu \mathrm{m}$.

songbirds and budgerigars, DM receives a telencephalic projection from the vocal nucleus of the archistriatum (RA in songbirds and AAc in budgerigars; Paton et al., 1981; Vicario, 1993; Reinke and Wild, 1998). DM also shows vocally induced ZENK expression in songbirds (Jarvis and Nottebohm, 1997; Mello and Ribeiro, 1998).

Other brain regions. We observed diffuse ZENK expression in some brain areas that varied in location and amount from animal to animal and thus did not appear to be a direct consequence of hearing and vocalizing. In the vocalizing animal shown, for example, large areas of the central-lateral telencephalon (Fig. 2E,F) showed increased expression relative to quiet controls, although at lower levels than those areas that showed consistent auditory or vocal ZENK induction. Interestingly, low-level induction occurred within a round structure in caudal Bas (Fig. 2E) that might correspond to auditory or beak somatosensory representative areas in Bas (Farabaugh and Wild, 1997). We did not observe this induction in the frontal sections of this or other vocalizing birds. It is possible that we missed it or that it occurred only in one animal.

\section{Quantitative analysis}

As shown by quantitative analysis of grains per cells, the range of increased $\mathrm{ZENK}$ expression relative to quiet controls was 5-7-fold in the hearing-induced regions (Fig. 9A, left set of bars) and 5-12-fold in the vocally induced regions (Fig. 9A, right set of bars). The hearing only group had no detectable increases in the seven telencephalic regions and one midbrain region that showed vocally regulated expression. In contrast, regions that showed hearing-induced expression were comparable for both hearing only and hearing and vocalizing animals. This analysis confirms that the hearing- and vocalizinginduced gene expression patterns are distinct. Furthermore, the amount of induced expression in the vocally
A.
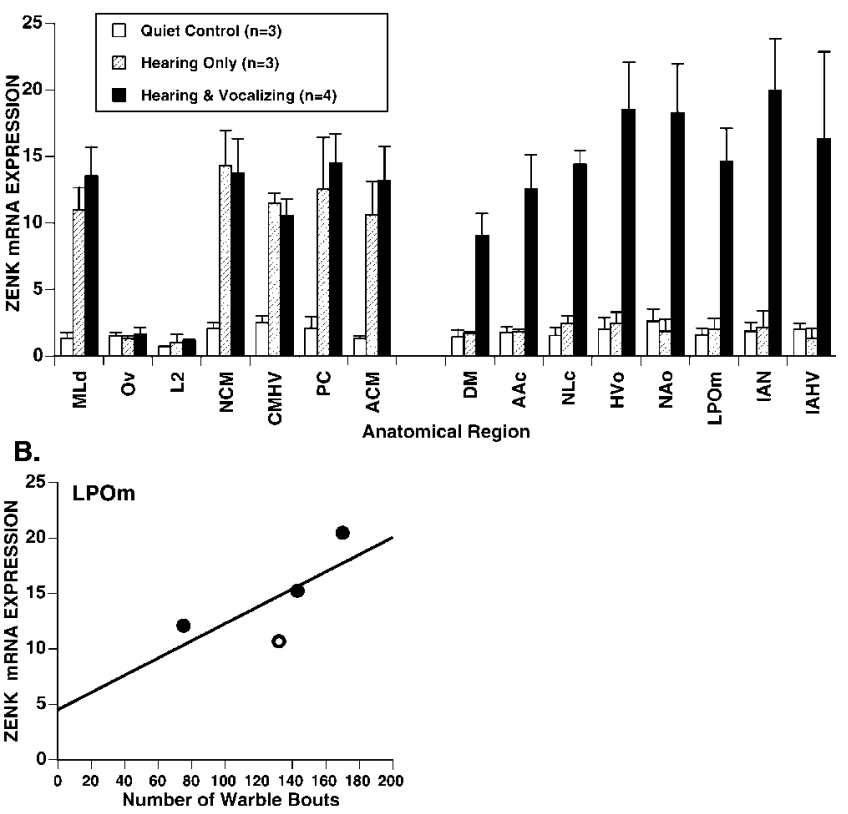

Fig. 9. Quantitative analysis of regions showing hearing- or vocalizing- induced ZENK expression. A: Left: Hearing-responsive regions. Right: Vocal-responsive regions. ZENK mRNA increase/cell (y axis) represents the average number of exposed silver grains/cell of a given region ( $\mathrm{x}$ axis) quantified from the in situ hybridizations using a previously described method (Jarvis and Nottebohm, 1997; Jarvis et al., 1998). Error bars represent SEM. In quiet controls, the average number of grains/cell across regions was two. All increases in the hearing only and hearing and vocalizing animals were significantly higher than those for quiet controls ( $P$ ranged from 0.001 to 0.02 ; two-tailed unpaired t-test). No significant differences were seen in: 1 ) the hearing-induced regions (left set of bars) between hearing only and hearing and vocalizing animals $(P=0.55-0.98) ; 2)$ the vocally induced regions (right set of bars) between quiet control and hearing only animals $(P=0.34-0.89)$, and 3 ) in field $\mathrm{L}$ and in $\mathrm{Ov}$ between any group $(P=0.18-0.91)$. The overall increase of expression/cell in LPOm of the hearing and vocalizing animals is lower than in some other nuclei, but its expression in Figures 2 and 3 appears higher because of LPOm's higher cell density relative to other nuclei. B: The amount of LPOm ZENK expression (y axis) in the hearing and vocalizing group was proportional to the amount of warble song bouts produced (x axis; $P=0.0029, \mathrm{r}=0.982$, linear regression, no-intercept model). This was not the case when the amount of expression was compared to the amount of calls produced $(P=0.275, \mathrm{r}=0.609$; not shown). Solid circles represent values of birds who produced most of their warbles, $>90 \%$, in an undirected manner. The open circle represents the one bird who produced approximately $50 \%$ of its warbles while facing, that is directed to, another bird.

activated regions, for example, in LPOm, was proportional to the amount of warble song produced (Fig. 9B). This was not the case when expression was compared to calls (not shown). Interestingly, one of the vocalizing birds produced approximately $50 \%$ of its warbles while facing another bird (directed warbles); this animal's expression levels in LPOm (Fig 9B, open circle) were lower than those in the other animals, whose vocalizations were undirected (Fig. 9B, solid circles). Although the number of animals used here is not high enough to make a strong conclusion, this observation falls in line with previous work in songbirds, where the context of singing affects ZENK expression in several vocal nuclei (Jarvis et al. 1998). 


\section{A. PARROT}

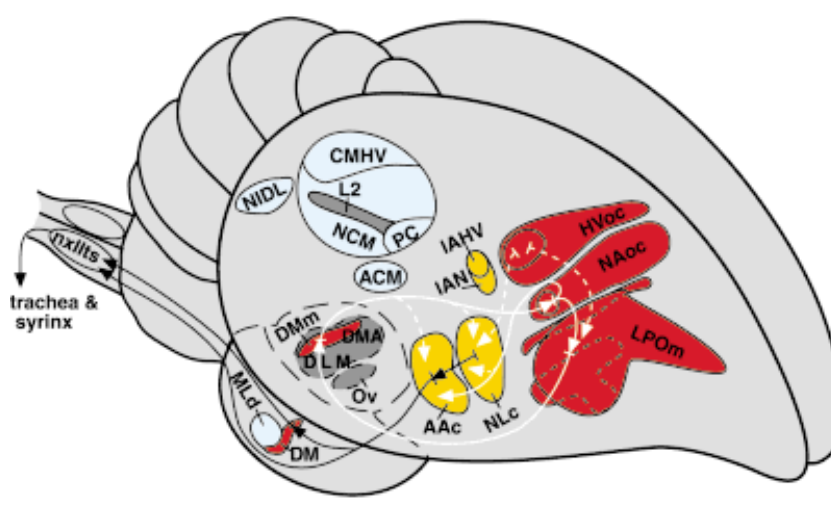

B. SONGBIRD

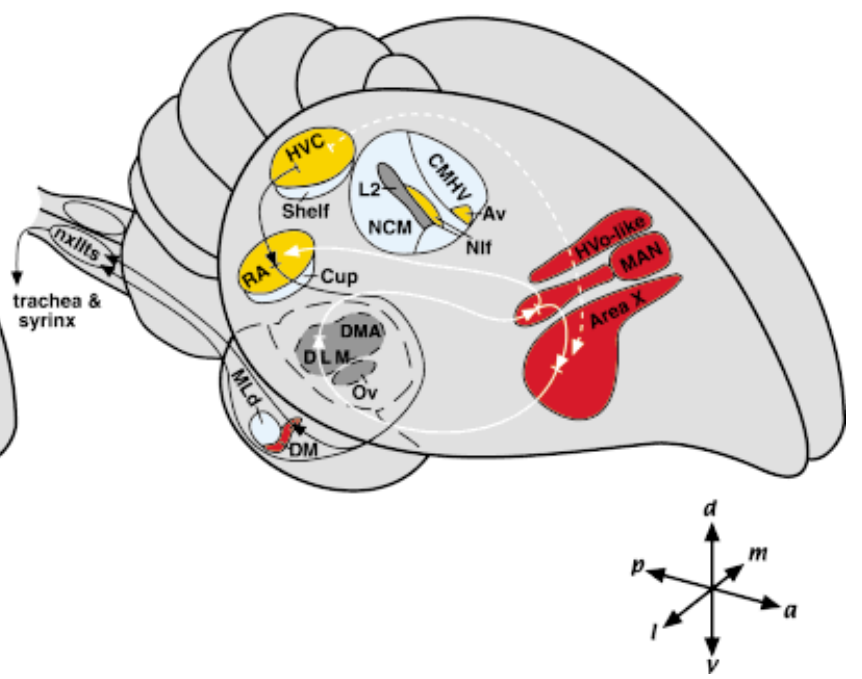

Fig. 10. Anatomical semi-three-dimensional summary of regions showing hearing- and vocalizing-induced ZENK expression in budgerigars $(\mathbf{A})$ and songbirds (B). Red regions designate vocally activated areas that are in similar brain locations between budgerigars and songbirds. Yellow regions designate areas of vocal activation that are differently positioned. Blue regions designate auditory activated areas. Grey regions designate structures known to be connected with auditory and vocal nuclei but showing very little or no ZENK activation. Similarly to what we found in songbirds (B; Mello and Clayton, 1994; Jarvis and Nottebohm, 1997), there is a distinct separation of budgerigar brain areas (A) that show ZENK activation either as a result of hearing conspecific vocalizations or with the act of vocalizing. One major difference is that the differently positioned clusters (yellow) in songbirds are embedded within auditory ZENK-activated regions (blue), whereas in budgerigars they are physically separate from these auditory regions. Vocally induced expression has not been clearly defined in or around songbird DLM (Jarvis and Nottebohm, 1997; Jin and Clayton, 1997; Jarvis et al., 1998; Mello and Ribeiro, 1998). Dashed lines of LPOm (B) indicate the LPOm extensions. Solid circles within NAoc and HVoc (B) represent the subdivisions of NAo and $\mathrm{HVo}$, respectively. Lateral and medial MAN are indicated as two separate shapes labeled MAN. Overlying the expression patterns are

\section{DISCUSSION}

Figure 10A summarizes a three-dimensional perspective of the ZENK expression patterns seen in the budgerigar brain during vocal communication. Figure 10B shows the same perspective in songbirds for comparison. Red regions indicate vocally activated areas that are in very similar brain locations between budgerigars and songbirds (the anterior-medial cluster containing three structures and DM); yellow regions indicate vocally activated areas that are differently positioned (the posterior-lateral and anterior-lateral clusters in budgerigars containing two structures each, and the four posterior structures in songbirds); blue regions indicate auditory activated areas; and dark gray regions indicate structures known to be connected with auditory and vocal nuclei, but that do not show a ZENK activation response. Overlying the expression patterns are lines and arrows to indicate the flow of information as inferred from known connectivity (see Fig. 10 legend for references). Similar to what we had found in lines and arrows to indicate the general flow of information as inferred from known connectivity (budgerigars: Paton et al., 1981; Striedter, 1994; Durand et al., 1997; Reinke and Wild, 1998; songbirds: Nottebohm et al., 1976, 1982; Bottjer et al., 1989; Vicario, 1993; Wild 1993; Johnson et al., 1995; Vates and Nottebohm, 1995; Foster et al., 1997; Vates et al., 1997; Foster and Bottjer, 1998). Arrowheads are where synapses are located. Black lines designate connections of the direct motor vocal pathway that are similar in both bird groups. Solid white lines designate connections of the indirect anterior-medial pathway that are similar in both bird groups, the cortical-striatalthalamic-cortical loop, and its output to the archistriatal nucleus. Dashed white lines designate connections with the anterior-medial pathway that are different between the two bird groups. A number of connections are not shown for the sake of simplicity and comprehension; these include medial portions of the anterior-medial pathway in songbirds (Foster et al., 1997; Foster and Bottjer, 1998; Jarvis et al., 1998), projections from the dorsal part of RA for songbirds (Vicario, 1993) and ventral part of AAc for budgerigars (Durand et al., 1997), projections of songbird RA onto other brainstem nuclei (Wild, 1994, 1997), connections of Nif and Av (Vates et al., 1996; Striedter and Yu, 1998), possible connections of lAN (Farabaugh and Wild 1997), and connections of the auditory pathways.

songbirds (Mello and Clayton, 1994; Jarvis and Nottebohm, 1997), there is a distinct separation of budgerigar brain areas that show hearing- and vocalizing-induced ZENK expression. Below we first discuss the functional and anatomical relevance of our findings for budgerigar vocal communication and then consider implications for the evolution of vocal learning in birds.

\section{FUNCTIONAL RELEVANCE}

Interpreting the $\mathrm{ZENK}$ induction response. ZENK, like other immediate early genes, is thought to require changes in electrophysiological activity to trigger synthesis of its mRNA (Sheng and Greenberg, 1990; Chaudhuri, 1997; Strippling et al., 1997). However, not all neuronal activity leads to ZENK induction. In songbirds, for example, increased electrophysiological activity occurs in field L2 neurons when birds hear an auditory stimulus (Leppelsack and Vogt, 1976; Chew et al., 1995), but without a consequent ZENK response (Mello and Clayton, 1994). 
Likewise, increased electrophysiological activity occurs in NCM neurons, although differentially so, when birds hear novel or familiar songs (Chew et al., 1995; Strippling et al., 1997), but ZENK is induced in NCM only with the novel songs (Mello and Clayton, 1994). Thus, neuronal depolarization appears to be a necessary (Sheng and Greenberg, 1990), but not sufficient, factor to induce ZENK mRNA synthesis. Therefore, the budgerigar brain areas that showed a ZENK response in the present study presumably had increased electrophysiological activity associated with vocal communication. Conversely, regions that did not show a ZENK response either did not have any activity change during vocal communication or were active without an ensuing ZENK response. One should bear this caveat in mind when interpreting the expression patterns discussed below.

Hearing-responsive regions. The $\mathrm{ZENK}$ expression domains observed in the hearing only group (Fig. 10A, blue regions) are likely involved in auditory processing and perceptual aspects of vocal communication. These structures are in close association with a core region formed by field L2, the main telencephalic target of the thalamic auditory nucleus Ov. In songbirds, electrophysiological and gene expression studies of structures around field L2 have revealed evidence suggesting their involvement in the auditory representation of song elements (Leppelsack and Vogt, 1976; Muller and Leppelsack, 1985; Mello and Ribeiro, 1998) and in the formation of song auditory memories (Chew et al., 1995, 1996; Jarvis et al., 1995; Mello et al., 1995; Strippling et al., 1997). Interestingly, lesions of budgerigar field L2 that include surrounding neostriatum appear not to affect acquisition and production of contact calls (Hall et al., 1994). Such lesion studies have not been reported in songbirds. Our auditory stimulus included mostly warbles, so we cannot fully compare the lesion and the gene activation results; however, it would be useful in future studies to determine whether different regions of the brain undergo gene activation during perception and production of warbles vs. calls.

Vocal-responsive regions. The nine ZENK expression domains observed exclusively in the hearing and vocalizing group (Fig. 10A, red and yellow structures) are likely involved in vocal production; these regions showed no detectable ZENK induction when birds just heard song playbacks but very marked ZENK induction with vocalizing. This result is consistent with the fact that structures within at least seven of these regions (HVo, NAo, LPOm, NLc, AAc, DMm, DM) are part of a pathway that eventually innervates the vocal organs (Paton et al., 1981; Striedter, 1994; Durand et al., 1997; Fig. 10A). The exact connectivity of the two other structures (lAN, lAHV) remains to be determined. However, an area overlying Bas of shape and location somewhat similar to those of IAN depicted in Figure 3F appears to be reciprocally connected with auditory fields L1 and L3 (Farabaugh and Wild, 1997). This same area may also receive auditory inputs from Bas (Striedter, 1994) and may project to the vocal nucleus HVo (Durand et al., 1997). The fact that there was no auditory ZENK response in $\mathrm{lAN}$ and $\mathrm{lAHV}$ or in the general area of the frontal telencephalon to which they belong is intriguing. This area shows electrophysiological responses to noise as well as playbacks of budgerigar vocalizations (Striedter, 1994; Wild et al., 1997a), and lesions to the underlying Bas affect the acquisition of contact calls (Hall et al., 1994). However, it is quite possible that the very large lesions made (Hall et al., 1994) included the overlying $1 \mathrm{AN}$ and $\mathrm{lAHV}$, affecting acquisition and/or production of warbles, much as lesions of song nuclei do in songbirds. Moreover, the electrophysiological studies were performed in anaesthetized animals (Striedter, 1994; Wild et al., 1997a). Recent studies in songbirds have shown that robust auditory-induced electrophysiological activity occurs in vocal nuclei of anaesthetized but not awake birds (Hessler and Doupe, 1997; Margoliash, 1997; Schmidt and Konishi, 1998; Dave et al., 1998), although there is a conflict of results pertaining to one vocal nucleus, HVC (Schmidt and Konishi, 1998; Dave et al., 1998). If these auditory responses are also diminished or absent in awake budgerigars, it is possible that what was thought to be auditory frontal neostriatum and hyperstriatum (Striedter, 1994) is really vocal IAN and lAHV. Alternatively, preliminary studies in the frontal neostriatum of awake budgerigars has shown that electrophysiological activity occurs during the production of calls and in response to hearing calls (Plumer and Striedter, 1997). If this latter result holds for IAN, then it would be one of the few nuclei that show an electrophysiological response in two different situations but ZENK gene activation in only one of them.

Possible consequences of ZENK induction. The cellular and behavioral consequences of the induction of ZENK and other immediate early genes in the brain are not well understood. The ZENK gene encodes a zinc-finger transcriptional regulator that binds to a specific sequence in the promoter regions of several other genes, potentially modulating their expression (Christy and Nathans, 1989). Two known ZENK targets are synapsin I (Thiel et al., 1994) and intermediate neurofilament (Pospelov et al., 1994), proteins involved in synaptic vesicle release and maintenance of neuronal cell structure, respectively. ZENK is thus in a position to translate neuronal activation into synaptic and structural plasticity. Such a role is consistent with the hypothesized involvement of immediate early genes in learning and memory (Goelet et al., 1981; Kaczmarek, 1993).

Parrots continue to learn and produce new vocalizations throughout their adult life (Dooling et al., 1987; Pepperberg, 1988; Pepperberg et al., 1991; Farabaugh et al., 1994; Banta and Pepperberg, 1995; Hall et al., 1997). As has been suggested for songbirds (Mello et al., 1995; Jarvis et al., 1995), the hearing-induced ZENK expression in budgerigar NCM and adjacent areas could be part of a molecular pathway involved in the formation of auditory memories. Likewise, the vocally induced expression in vocal nuclei may be involved in the formation of "new" motor memories for vocal production. However, this simple view does not hold up to all known observations. In songbirds robust vocally induced expression is found in species that continue to produce new as well as stable adult song (Jarvis and Nottebohm, 1997; Jarvis et al. 1997; Jin and Clayton, 1997; Kimbo and Doupe, 1997; Mello and Ribeiro, 1998). Instead, as has been proposed for songbirds (Jarvis and Nottebohm, 1997), the vocally induced ZENK expression in budgerigars may be involved in replenishing cellular protein stores that are used up during the act of vocalizing or in producing proteins that strengthen synaptic connections to maintain what is "already known." The current study does not resolve this issue but suggests that the functional consequences will be similar for both songbirds and parrots. 


\section{Anatomical relevance}

In our study, the functional boundaries of some regions showing vocally activated ZENK expression conform to previously described cytoarchitectonic borders defined by Nissl staining or to connectivity borders revealed by tracttracing studies (Paton et al., 1981; Striedter, 1994; Durand et al., 1997; Reinke and Wild, 1998). In this category fall two nuclei in the telencephalon, NLc and AAc, and one in the midbrain, DM. However, for the anterior-medial cluster (the HVo complex, NAo complex, and LPOm), there is a marked mismatch between the ZENK-defined boundaries and previously defined cytoarchitectonic features and connectivity. An explanation for this discrepancy could be that the ZENK mapping strategy revealed the full functional domain occupied by $\mathrm{HVo}$, NAo, and LPOm, whereas definitions of these regions based solely on Nissl staining and tract tracing are incomplete. We also examined structures in both parasagittal and frontal planes, which had not been done previously. This was particularly useful in defining complex structures, such as LPOm and its extensions. In the one case where Nissl staining in the parasagittal plane had been examined (Fig. 1 of Durand et al., 1997), the cytoarchitectonic boundaries formed by both the HVo and the NAo complexes were closer to the larger functional boundaries we report here (our Fig. 2B,C).

For projections that are topographically organized, tracers placed into a portion of a particular nucleus will most probably reveal only a portion of connecting structures. In such cases, tract tracing may be limited in its ability to define boundaries of brain structures in their entirety. In the original tracing studies of vocal pathways in budgerigars, for example, only the dorsal part of AAc was defined (Paton et al., 1981); its ventral half was revealed only after multiple injections were placed in a more distributed fashion (Durand et al., 1997). The larger size of AAc, that includes the dorsal and ventral subdivisions, conforms to the functional boundary revealed by vocally induced ZENK expression. A testable prediction is that multiple small injections that completely fill the core and surrounding domains of the HVo and NAo complexes and LPOm may reveal similarly sized and shaped structures to those identified in the present study. Alternatively, the surrounding domains may have local circuitry that processes information for use by the core domains, of HVo and NAo, for example, which then would send information to other vocal nuclei. At any rate, because the exact boundaries of the functionally activated regions can be difficult to define by Nissl staining alone, it may be useful in future studies to use vocally induced gene expression to facilitate their localization when determining connectivity.

Further evidence for multiple subdomains comes from studies in budgerigars that have examined the presence of other gene products known to be selectively expressed in songbird vocal nuclei. These are: the estrogen (E; Gahr et al., 1993), cholinergic, and NMDA receptors (Ball, 1994); choline acetyltransferase (ChAT) and acetylcholinesterase (AChE; Cookson et al., 1996); and methionine enkephalin (mENK; Durand et al., 1998). Selective AChE and mENK expression was found outside the boundaries of the thenknown budgerigar vocal nuclei with patterns partly similar to those described here for vocally induced ZENK. This includes the HVo and NAo complexes (our ZENK expression boundaries of Fig. 3D and E are similar to Figs. 1 and
TABLE 1. Regions of Similarity Between Budgerigar and Songbird Brains That Show Hearing- or Vocalizing-Induced ZENK Expression ${ }^{1}$

\begin{tabular}{lllll}
\hline $\begin{array}{l}\text { Brain } \\
\text { subdivision }\end{array}$ & $\begin{array}{c}\text { Auditory } \\
\text { parrot }\end{array}$ & $\begin{array}{l}\text { Auditory } \\
\text { songbird }\end{array}$ & $\begin{array}{c}\text { Vocal } \\
\text { parrot }\end{array}$ & $\begin{array}{c}\text { Vocal } \\
\text { songbird }\end{array}$ \\
\hline Hyperstriatum & CMHV & CMHV & HVo & HVo \\
& NCM, L1, L3 & NCM, L1, L3 & 1AHV (?) & NLc \\
Neostriatum & NIDL & HVC shelf & NAo & HVC \\
& Field L2 (-) & Field L2 (-) & 1AN (?) & NIf (?) \\
& ACM & RA cup & AAc & RA \\
Archistriatum & PC & PC & LPOm & Area X \\
Paleostriatum & Ov (-) & Ov (-) & DMm & DLM (+) \\
Thalamus & MLd & MLd & DM & DM \\
Midbrain & & & &
\end{tabular}

${ }^{1}$ Interconnecting structures that show very little or no ZENK gene expression response are also included with a minus sign. Brain areas are first broken down by subdivision, then by behavioral relevance (auditory or vocal), and then by subregion of activation. The question mark for NIf with $1 \mathrm{AN}$ and Av with $1 \mathrm{AHV}$ means that the proposed similarities are tentative suggestions. For abbreviations, see list.

5 of Cookson et al., 1996, and Fig. 2 of Durand et al., 1998), the dorsal and ventral LPOm extensions (our Fig. $3 \mathrm{H}$ and I are similar to Figs. 2.4 and 2.5 of Durand et al., 1998), and IAN/lAHV (our Fig. 3E is similar to Fig. 12B of Durand et al., 1998). However, the core domains of the HVo and NAo complexes, i.e., HVo and NAo, still have higher AChE and mENK immunoreactivity relative to their medial surround (Cookson et al., 1996; Durand et al., 1998). Such a functional difference within the HVo and NAo complexes was not delineated by the ZENK expression patterns.

Recently, functional subdivisions within vocal control nuclei have been described in songbirds. Differential ZENK activation was observed in zebra finch lateral magnocellular nucleus of the neostriatum (IMAN), lateral area $\mathrm{X}$, and the major ventral portion of the robust nucleus of the archistriatum (RA) depending on whether the birds sang directed or undirected song (Jarvis et al., 1998). These subdivisions had not been noted in prior vocal gene mapping studies (Jarvis and Nottebohm, 1997; Jin and Clayton, 1997; Kimbo and Doupe, 1997; Mello and Ribeiro, 1998), because the social context and type of vocal behavior were not considered. Budgerigars in the current study vocalized mostly in an undirected manner, which for songbirds induces ZENK throughout the vocal system (Jarvis et al., 1998). However, the one bird that produced approximately half of its vocalizations while facing another bird had lower LPOm expression than the others, consistent with findings in songbird area X (Jarvis et al., 1998). Thus, it is possible that in different behavioral contexts ZENK will also reveal functional differential responses within budgerigar vocal nuclei delineating subdomains that are discernible with Nissl, AChE, and mENK staining. Taken together, the results suggest that budgerigar vocal control areas are more complex in their topography than was previously realized.

\section{Evolutionary relevance}

Although the results described here are based on one parrot species, several aspects of the results contribute some intriguing insights into the evolution of vocal learning and associated neural pathways in birds. Although obvious differences exist between the auditory and the vocal ZENK expression maps of budgerigars and songbirds, we are struck by the similarities (Fig. 10, Table 1), considering that vocal learning and the associated structures are thought to have evolved independently. First, in 
both, the auditory ZENK response is distinctly separate from the vocal. The reverse, i.e., whether the vocal response is independent of auditory responses and feedback, as occurs in songbirds (Jarvis and Nottebohm, 1997; Kimbo and Doupe, 1997), was not tested here in budgerigars; this requires examining vocally induced gene expression in deafened animals. Second, both groups have evolved three anterior-medial telencephalic vocal nuclei (Fig 10, red regions) at nearly the same brain locations but with different shapes. Third, there is close correspondence of brain regions that do and do not have ZENK activation. For example, within the auditory pathway of both groups, MLd and NCM show ZENK induction, whereas interconnecting structures between these regions, Ov and field L2, do not show detectable ZENK induction. Fourth, there is a close correspondence of brain region size showing ZENK expression. For example, in both bird groups, the largest vocal motor region (LPOm/area $\mathrm{X}$ ) is within the paleostriatum and the largest auditory region (NCM) is within the neostriatum (Fig. 10). Based on these comparisons and those of previous studies (Paton et al., 1981; Striedter, 1994; Durand et al., 1997), we suggest three evolutionary histories (Fig. 10): 1) a caudal auditory pathway (blue) that is highly similar, 2) an anterior-medial vocal pathway (red) that is somewhat similar, and 3) a posterior-lateral vocal pathway (yellow) that is more different.

The caudal auditory pathway (Fig. 10, blue) is probably inherited from a common avian ancestor, because distantly related avian species, such as chickens, doves, pigeons, budgerigars, and songbirds (Fig. 1), have similar anatomical structures and connectivity (Karten, 1967, 1968; Kelly and Nottebohm, 1979; Muller and Scheich, 1985; Brauth et al., 1987; Brauth and McHale, 1988; Fortune and Margoliash, 1992, 1995; Wild et al., 1993; Vates et al., 1996; Metzger et al., 1998; Mello et al., 1998). It has been proposed that in budgerigars the rostral auditory pathway, with Bas as the main telencephalic receiving area, is more important for learned vocal communication than the caudal auditory pathway, which was thought to be more important in songbirds (Hall et al., 1994; Striedter, 1994). However, the gene expression results, combined with recent studies showing projections from the caudal auditory areas L1 and L3 into anterior vocal nuclei of budgerigars (Durand et al., 1997; Farabaugh and Wild, 1997), suggest that the caudal auditory pathway may play a more significant role in learned vocal communication in budgerigars than was previously thought.

Nuclei of the anterior-medial vocal pathway (Fig. 10, red) in both bird species are interconnected to form a cortical-striatal-thalamic-cortical loop (Okuhata and Saito, 1987; Bottjer and Johnson, 1997; Durand et al., 1997; Jarvis et al., 1998) that consists of projections from avian cortical-like structures (MAN for songbirds, NAo and HVo for budgerigars) to the basal ganglia's striatum (area X/LPOm) to the dorsal thalamus (DLM/DMm), and back to the cortex (MAN/NAo; Fig. 10, solid white arrows). This cortical-striatal-thalamic-cortical loop follows a design that is present in areas outside of the avian vocal system and is basic to motor systems in the brain of birds, mammals, and possibly reptiles (Karten and Shimizu, 1989; Karten, 1991; Medina and Reiner, 1995; Veenman et al., 1995, 1997; Bottjer and Johnson, 1997; Durand et al., 1997; Medina et al., 1997; Jarvis et al., 1998; Marin et al., 1998). This pathway in songbirds is involved in vocal learning (Sohrabji et al., 1990; Scharff and Nottebohm,
1991), possibly in song maintenance (Benton et al., 1998), and in the social context of singing (Jarvis et al., 1998; Hessler and Doupe, 1999). Until recently, HVo had been found only in budgerigars (Striedter, 1994; Durand et al., 1997). However, singing induces ZENK expression in an HVo-like structure in the hyperstriatum immediately overlying MAN in songbirds (Jarvis et al., 1998; Fig. 10). Although the connectivity of the HVo-like nucleus remains to be determined in songbirds, the fact that three structures are located in very similar positions in both bird groups, i.e., beginning near the midline and extending laterally to about halfway into each brain hemisphere overlying each other in three different subdivisions of the telencephalon, suggests a conserved trait. If these vocal structures evolved independently in these two bird orders, then they did so within a preexisting framework (Margoliash et al., 1994; Brenowitz, 1997; Durand et al., 1997; Margoliash, 1997). Alternatively, nonvocal learning orders may contain an anterior forebrain vocal pathway, but previous tract tracing and staining approaches (Nottebohm, 1972, 1980; Bonke et al., 1979; Kroodsma and Konishi, 1991; Wild et al., 1997b) have failed to detect it. This possibility can now be tested by using our gene mapping approach in nonvocal learning orders.

The posterior-lateral vocal pathway (Fig. 10, larger yellow regions) in both bird groups consists of a neostriatal projection to an archistriatal nucleus that eventually projects to motor neurons that innervate the vocal organ (HVC to RA to DM and nXIIts for songbirds and NLc to dorsal AAc to DM and nXIIts for budgerigars; Fig 10, black arrows). However, there are marked differences in the exact brain location and in the connections with the anterior-medial pathway (Paton et al., 1981; Striedter, 1994; Durand et al., 1997; Fig. 10, dashed white arrows). Our present results show that they also differ in their position relative to auditory regions. In songbirds, HVC and RA are embedded within caudal auditory forebrain regions that show an auditory ZENK response (Mello and Clayton, 1994), the HVC shelf and RA cup, respectively (Fig. 10B; Kelley and Nottebohm, 1979; Vates et al., 1996; Mello et al., 1998). In budgerigars, contrary to what has been predicted (Striedter, 1994), we did not find analogous regions surrounding NLc and AAc. Instead, NLc and AAc appear to be separate from the respective auditory regions in the neostriatum and archistriatum, NIDL and ACM, respectively (Fig. 10A, Table 1). It is still possible, though, that the budgerigar NLc and AAc are embedded in auditory regions that do not have a ZENK response. Nevertheless, the available results suggest that, if the posteriorlateral vocal pathway evolved independently in songbirds and parrots, the songbird pathway may have been derived from a preexisting caudal auditory pathway (Margoliash et al., 1994) and the parrot pathway may have been derived separately from the preexisting caudal auditory pathway. Alternatively, if the posterior-lateral vocal pathway derived from a common ancestor, then the pathway may have moved from its original location to the regions that it presently occupies, i.e., caudomedially into the caudal auditory pathway in songbirds, and/or anteriolaterally away from the caudal auditory pathway in budgerigars. However they evolved, it is clear that vocal learning occurs in both cases.

The two budgerigar vocal structures of the anteriorlateral cluster (IAN and $\mathrm{AHV}$ ) do not appear to have songbird counterparts, as determined by any of the meth- 
ods of which we are aware. Likewise, two songbird vocal nuclei, avalanche (Av) of the hyperstriatum and nucleus interfacialis (NIf) of the neostriatum (Fig. 10), which show a vocal ZENK response (Jarvis and Nottebohm, 1997; Jin and Clayton, 1997; Jarvis et al., 1998), do not appear to have budgerigar counterparts as determined by our gene expression analysis. An NIf-like structure has been reported in budgerigars, based on tract tracing (Hall et al., 1994), but this finding has been questioned (Reinke and Wild, 1998). It is also possible that our analysis failed to identify an NIf-like structure if, as in songbirds, NIf is small and located next to auditory regions that show a ZENK response (Jarvis et al., 1998), making it difficult to locate by this technique. Alternatively, budgerigar IAN and lAHV may be counterparts to songbird NIf and Av, respectively, insofar as they are in the same brain subdivisions. If this is so, then, like NLc and AAc, lAN and IAHV may have evolved separately from the auditory regions of field L1 (next to L2) and CMHV, in which NIf and Av are, respectively, embedded.

A similarity that we find particularly intriguing is that, in both bird groups, auditory processing and vocal production involve the participation of one or more subregions from each major brain subdivision (Table 1). Studies in the pigeon have shown that the various avian telencephalic subdivisions derived from the embryonic dorsal ventricular ridge (the hyperstriatum ventrale, the neostriatum, the ectostriatum, and the archistriatum) contain cell groups and projections comparable to those found in the different layers of the mammalian neocortex, whereas the paleostriatum corresponds to the striatum of the mammalian basal ganglia (Karten and Shimizu, 1989; Karten, 1991; Medina and Reiner, 1995; Striedter, 1997; Veenman et al., 1995, 1997; Marin et al., 1998). A corollary to this hypothesis is that an avian forebrain pathway conveying specific sensory or motor information should contain nuclei from each of these major brain subdivisions. The fact that auditory processing and vocal production involve the participation of at least one subregion from each avian subdivision (Table 1) is consistent with this view. Moreover, the different relative contributions from the avian paleostriatum to vocal motor and auditory pathways (i.e., a larger motor nucleus, area X/LPOm, vs. a smaller auditory one, PC), is consistent with the fact the mammalian striatum has larger regions dedicated to motor functions than to sensory functions (Alexander et al., 1986). If vocal learning really did evolve independently, then these findings would suggest that the basic organization of the vertebrate amniote telencephalon may impose strong constraints on how brain pathways subserving vocal learning in birds could evolve.

\section{CONCLUSIONS}

In summary, this study utilizes hearing- and vocalizingdriven gene expression to functionally and anatomically characterize structures involved in vocal communication throughout the brain of a parrot. The results show a distinct separation of auditory and vocal responsive regions. Based on comparison to previous tract-tracing studies, the structures described belong to three distinct pathways: 1) a caudal auditory, 2) an anterior-medial vocal, and 3) a posterior-lateral vocal. The functionally active regions are somewhat larger and different in shape than previously described. More similarities, rather than dif- ferences, are found to structures of the auditory and vocal pathways of songbirds. For structures in the caudal auditory and anterior-medial vocal pathways, the major difference between budgerigars and songbirds appears to be their shape, rather than their exact brain location. For structures in the posterior-lateral vocal pathway, the location and association with auditory regions are different between the two avian groups: In songbirds they are in close apposition to nuclei of the caudal auditory pathway, whereas in budgerigars they are located distantly from the latter. Each of these pathways may have had a different evolutionary history. Considering the 65 million years of evolution that separates songbirds and parrots from their common ancestor (Feduccia, 1995, 1996; Miyaki et al., 1998), if their vocal nuclei evolved independently, then convergence on similar molecular and anatomical substrates would suggest that vertebrate brain organization and possible epigenetic factors place strong constraints on how such structures could evolve.

\section{ACKNOWLEDGMENTS}

We thank Fernando Nottebohm for use of his laboratory space to perform these experiments and Sidarta Ribeiro for assistance during the beginning stages of this project. We thank Sarah Durand for very useful discussions in the preparation of this report and critical reading of the manuscript, Pam Banta for critical reading, and Larry Katz for use of his image analysis system. We also thank Lisa Moore for her very useful assistance with the preparation of the manuscript. This work was supported by an NIMH research training grant, the Kluge Trust Fund, and Duke University Funds to E.D.J. and NIH grant DC02853 to C.V.M.

\section{REFERENCES}

Aldridge JW, Berridge KC. 1998. Coding of serial order by neostriatal neurons: a "natural action" approach to movement sequence. J Neurosci 18:2777-2787.

Alexander GE, DeLong MR, Strick PL. 1986. Parallel organization of functionally segregated circuits linking basal ganglia and cortex. Annu Rev Neurosci 9:357-381.

Ball GF. 1994. Neurochemical specializations associated with vocal learning and production in songbirds and budgerigars. Brain Behav Evol 44:234-246.

Ball GF, Gentner TQ. 1998. They're playing our song: gene expression and birdsong perception. Neuron 21:271-274.

Banta PA, Pepperberg IM. 1995. Learned English vocalizations as a model for studying the budgerigar (Melopsittacus undulatus) warble song. Soc Neurosci Abstr 21:964.

Baptista LF, Schuchmann K-L. 1990. Song learning in the Anna hummingbird (Calypte anna). Ethology 84:15-26.

Benton S, Nelson DA, Marler P, DeVoogd TJ. 1998. Anterior forebrain pathway is needed for stable song expression in adult male whitecrowned sparrows (Sonotrichia leucophyrys). Behav Brain Res 96:135150.

Bonke BA, Bonke D, Scheich H. 1979. Connectivity of the auditory forebrain nuclei in the guinea fowl (Numida meleagris). Cell Tissue Res 200:101-121.

Bottjer SW, Johnson F. 1997. Circuits, hormones, and learning: vocal behavior in songbirds. J Neurobiol 33:602-618.

Bottjer SW, Halsema KA, Brown SA, Miesner EA. 1989. Axonal connections of a forebrain nucleus involved with vocal learning in zebra finches. J Comp Neurol 279:312-326.

Brauth SE, McHale CM. 1988. Auditory pathways in the budgerigar II. Intratelencephalic pathways. Brain Behav Evol 32:193-207.

Brauth SE, McHale CM, Brasher CA, Dooling RJ. 1987. Auditory path- 
ways in the budgerigar I. Thalamo-telencephalic projection. Brain Behav Evol 30:174-199.

Brauth SE, Heaton JT, Durand SE, Liang W, Hall WS. 1994. Functional anatomy of forebrain auditory pathways in the budgerigar (Melopsittacus undulatus). Brain Behav Evol 44:210-233.

Brenowitz EA. 1991. Evolution of the vocal control system in the avian brain. Semin Neurosci 3:399-407.

Brenowitz EA. 1997. Comparative approaches to the avian song system. Neurobiology 33:517-531.

Caldwell MC, Caldwell DK. 1972. Vocal mimicry in the whistle mode by an Atlantic bottlenosed dolphin. Cetology 9:1-8.

Chaudhuri A. 1997. Neural activity mapping with inducible transcription factors. Neuroreport 8:5-9.

Chew SJ, Mello CV, Nottebohm F, Jarvis E, Vicario DS. 1995. Decrements in auditory responses to a repeated conspecific song are long-lasting and require two periods of protein synthesis in the songbird forebrain. Proc Natl Acad Sci USA 92:3406-3410.

Chew SJ, Vicario DS, Nottebohm F. 1996. Quantal duration of auditory memories. Science 274:1909-1914.

Christy B, Nathans D. 1989. DNA binding site of the growth factorinducible protein Ziff 268. Proc Natl Acad Sci USA 86:8737-8741.

Clayton DF. 1997. Role of gene regulation in song circuit development and song learning. Neurobiology 33:549-571.

Cookson KK, Hall WS, Heaton JT, Brauth SE. 1996. Distribution of choline acetyltransferase in vocal control nuclei of the budgerigar (Melopsittacus undulatus). J Comp Neurol 368:220-235.

Dave AS, Yu AC, Margoliash D. 1998. Behavioral state modulation of auditory activity in a vocal motor system. Science 282:2250-2254.

Dooling RJ, Gephart BF, Price PH, McHale C, Brauth SE. 1987. Effects of deafening on the contact call of the budgerigar (Melopsittacus undulatus). Anim Behav 35:1264-1266.

Durand SE, Tepper JM, Cheng MF. 1992. The shell region of nucleus ovoidalis: a subdivision of the avian auditory thalamus. J Comp Neurol 323:495-518.

Durand SE, Heaton JT, Amateau SK, Brauth SE. 1997. Vocal control pathways through the anterior forebrain of a parrot (Melopsittacus undulatus). J Comp Neurol 377:179-206.

Durand SE, Liang W, Brauth SE. 1998. Methionine enkephalin immunoreactivity in the brain of the budgerigar (Melopsittacus undulatus): similarities and differences with respect to oscine songbirds. J Comp Neurol 393:145-168.

Esser K-H. 1994. Audio-vocal learning in a non-human mammal: the lesser spear-nosed bat Phyllostomus discolor. Neuroreport 5:1718-1720.

Farabaugh SM, Wild JM. 1997. Reciprocal connections between primary and secondary auditory pathways in the telencephalon of the budgerigar (Melopsittacus undulatus). Brain Res 747:18-25.

Farabaugh SM, Linzenbold A, Dooling RJ. 1994. Vocal plasticity in budgerigars (Melopsittacus undulatus): evidence for social factors in the learning of contact calls. J Comp Psychol 108: 81-92.

Feduccia A. 1995. Explosive evolution in tertiary birds and mammals. Science 267:637-638.

Feduccia A. 1996. The origin and evolution of birds. New Haven, CT: Yale University Press.

Fortune ES, Margoliash D. 1992. Cytoarchitectonic organization and morphology of cells of the field L complex in male zebra finches (Taeniopygia guttata). J Comp Neurol 325:388-404.

Fortune ES, Margoliash D. 1995. Parallel pathways and convergence onto $\mathrm{HVc}$ and adjacent neostriatum of adult zebra finches (Taeniopygia guttata). J Comp Neurol 360:413-441.

Foster EF, Bottjer SW. 1998. Axonal connections of the high vocal center and surrounding cortical regions in juvenile and adult male zebra finches. J Comp Neurol 397:118-138.

Foster EF, Mehta RP, Bottjer SW. 1997. Axonal connections of the medial magnocellular nucleus of the anterior neostriatum in zebra finches. $J$ Comp Neurol 382:364-381.

Gahr M, Guttinger H-S, Kroodsma DE. 1993. Estrogen receptors in the avian brain: survey reveals general distribution and forebrain areas unique to songbirds. J Comp Neurol 327:112-122.

Gaunt SLL, Baptista LF, Sanchez JE, Hernandez D. 1994. Song learning as evidenced of song sharing in two hummingbird species (Colibri coruscans and C. thalassinus). Auk 111:87-103.

Goelet P, Castelucci V, Schacher S, Kandel E. 1981. The long and short of long-term memory—a molecular framework. Nature 332:419-422.
Guinee LH, Payne KB. 1988. Rhyme-like repetitions in songs of humpback whales. Ethology 79:295-306.

Hall WS, Cohen PL, Brauth SE. 1993. Auditory projections to the anterior telencephalon in the budgerigar. Brain Behav Evol 41:97-116.

Hall WS, Brauth SE, Heaton JT. 1994. Comparison of the effects of lesions in nucleus basalis and field " $L$ " on vocal learning and performance in the budgerigar (Melopsittacus undulatus). Brain Behav Evol 44:133148.

Hall WS, Cookson KK, Heaton JT, Roberts T, Shea SD, Brauth SE. 1997. Audio-vocal learning in budgerigars. Ann NY Acad Sci 807:352-367.

Hessler NA, Doupe AJ. 1997. Singing-related neural activity in anterior forebrain nuclei of adult zebra finch. Soc Neurosci Abs 23:245.

Hessler NA, Doupe AJ. 1999. Social context modulates singing-related neural activity in the songbird forebrain. Nature Neurosci 2:209-211.

Jarvis ED, Nottebohm F. 1997. Motor-driven gene expression. Proc Natl Acad Sci USA 94:3406-3410.

Jarvis ED, Mello CV, Nottebohm F. 1995. Associative learning and stimulus novelty influence the song-induced expression of an immediate early gene in the canary forebrain. Learning Memory 2:62-80.

Jarvis ED, Schwabl H, Ribeiro S, Mello CV. 1997. Brain gene regulation by territorial singing behavior in freely ranging songbirds. Neuroreport 8:2073-2077.

Jarvis ED, Scharff C, Grossman MR, Ramos JA, Nottebohm F. 1998. For whom the birds sings: context-dependent gene expression. Neuron 21:775-788.

Jin H, Clayton DF. 1997. Localized changes in immediate-early gene regulation during sensory and motor learning in zebra finches. Neuron 19:1049-1059.

Johnson F, Sablan MM, Bottjer SW. 1995. Topographic organization of a forebrain pathway involved with vocal learning in zebra finches. $J$ Comp Neurol 358:260-278.

Kacmarek L. 1993. Molecular biology of vertebrate learning: is c-fos a new beginning. J Neurosci Res 34:377-381.

Karten JH. 1967. The organization of the ascending auditory pathway in the pigeon (Columbia livia) I. Diencephalic projection of the inferior colliculus (nucleus mesencephali lateralis, pars dorsalis). Brain Res 6:409-427.

Karten JH. 1968. The ascending auditory pathway in the pigeon (Columbia livia) II. Telencephalic projections of the nucleus ovoidalis thalami. Brain Res 11:134-153.

Karten JH. 1991. Homology and evolutionary origins of the "neocortex." Brain Behav Evol 38:264-272.

Karten JH, Shimizu T. 1989. The origins of neocortex: connections and laminations as distinct events in evolution. J Cogn Neurosci 1:291-301.

Kelley DB, Nottebohm F. 1979. Projections of a telencephalic auditory nucleus-field L-in the canary. J Comp Neurol 183:455-470.

Kimbo RR, Doupe AJ. 1997. FOS is induced by singing in distinct neuronal populations in a motor network. Neuron 18:315-325.

Konishi M, Nottebohm F. 1969. Experimental studies in the ontogeny of avian vocalizations. In: Hinde RA, editor. Bird vocalizations. Cambridge: Cambridge University Press. p 29-48.

Kroodsma DE. 1982. Learning and the ontogeny of sound signals in birds. In: Kroodsma DE, Miller EH, Ouellet H, editors, Acoustic communication in birds. New York: Academic Press. p 1-23.

Kroodsma D, Konishi M. 1991. A suboscine bird (eastern phoebe, Seynoris phoebe) develops normal song without auditory feedback. Anim Behav 42:477-487.

Leppelsack HJ, Vogt M. 1976. Responses of auditory neurons in the forebrain of a songbird to stimulation with species specific sounds. J Comp Physiol A 107:263-274.

Long KD, Salbaum M. 1998. Evolutionary conservation of the immediateearly gene ZENK. Mol Biol Evol 15:284-292

Marin O, Smeets WJAJ, Gonzalez A. 1998. Evolution of the basal ganglia in tetrapods: a new perspective based on recent studies in amphibians. TINS 21:487-493.

Margoliash D. 1997. Functional organization of forebrain pathways for song production and perception. J Neurobiol 33:671-693.

Margoliash D, Fortune ES, Sutter ML, Yu AC, Wren-Hardin BD, Dave A 1994. Distributed representation in the song system of oscinces: evolutionary implications and functional consequences. 44:247-264.

Marler P. 1970. Bird song and speech development: could there be parrallels? Am Sci 58:669-673.

Marler P. 1997. Three models of song learning: evidence from behavior. J Neurobiol 33:501-516. 
Medina L, Reiner A. 1995. Neurotransmitter organization and connectivity of the basal ganglia in vertebrates: implications for the evolution of the basal ganglia. Brain Behav Evol 46:235-258.

Medina L, Veenman CL, Reiner A. 1997. Evidence for a possible avian dorsal thalamic region comparable to the mammalian ventral anterior, ventral lateral, and oral ventroposterolateral nuclei. J Comp Neurol 384:86-108

Mello CV. 1998. Auditory experience, gene regulation and auditory memories in songbirds. Ciencia Cultura 50:189-195.

Mello CV, Clayton DF. 1994. Song-induced ZENK gene expression in auditory pathways of songbird brain and its relation to the song control system. J Neurosci 14:6652-6666.

Mello CV, Ribeiro S. 1998. ZENK protein regulation by song in the brain of songbirds. J Comp Neurol 393:426-438.

Mello CV, Vicario DS, Clayton DF. 1992. Song presentation induces gene expression in the songbird forebrain. Proc Natl Acad Sci USA 89:68186822.

Mello CV, Nottebohm F, Clayton DF. 1995. Repeated exposure to one song leads to a rapid and persistent decline in an immediate early gene's response to that song in the zebra finch telencephalon. J Neurosci 15:6919-6925.

Mello CV, Jarvis ED, Denisenko N, Rivas M. 1997. Isolation of songregulated genes in the brain of songbirds. In: Liang $\mathrm{P}$, Pardee $\mathrm{AB}$, editors. Methods in molecular biology, Vol. 85: differential display methods and protocols. New Jersey: Humana Press. p 205-217.

Mello CV, Vates GE, Okuhata S, Nottebohm F. 1998. Descending auditory pathways in the adult male zebra finch (Taeniopygia guttata). J Comp Neurol 395:137-160.

Metzger M, Jiang S, Braun K. 1998. Organization of the dorsocaudal neostriatal complex: a retrograde and anterograde tracing study in the domestic chick with special emphasis on pathways relevant to imprinting. J Comp Neurol 395:380-404.

Miyaki CM, Matioli SR, Burke T, Wajntal A. 1998. Parrot evolution and paleogeographical events: mitochondrial DNA evidence. Mol Biol Evol 15:544-551.

Muller SC, Leppelsack HJ. 1985. Feature extraction and tonotopic organization of the avian auditory forebrain. Exp Brain Res 59:587-599.

Muller SC, Scheich H. 1985. Functional organization of the avian auditory field L: a comparative 2DG study. J Comp Physiol A 156:1-12.

Nastiuk KL, Mello CV, George JM, Clayton DF. 1994. Immediate-early gene responses in the avian song control system: cloning and expression analysis of the canary c-jun cDNA. Mol Brain Res 27:299-309.

Nottebohm F. 1972. The origins of vocal learning. Am Naturalist 106:116140 .

Nottebohm F. 1980. Brain pathways for vocal learning in birds: a review of the first 10 years. Progr Psychobiol Physiol Psychol 9:85-124.

Nottebohm F, Nottebohm M. 1971. Vocalizations and breeding behaviour of surgically deafened ring doves Streptopelia risoria. Anim Behav 19:313-328.

Nottebohm F, Stokes TM, Leonard CM. 1976. Central control of song in the canary, Serinus canaria. J Comp Neurol 165:457-486.

Nottebohm F, Kelley DB, Paton JA. 1982. Connections of vocal control nuclei in the canary telencephalon. J Comp Neurol 207:344-357.

Okuhata S, Saito N. 1987. Synaptic connection of thalamo-cerebral vocal nuclei of the canary. Brain Res Bull 18:35-44.

Paton JA, Manogue KR, Nottebohm F. 1981. Bilateral organization of the vocal control pathway in the budgerigar, Melopsittacus undulatus. J Neurosci 1:1279-1288

Pepperberg IM. 1988. The importance of social interaction and observation in the acquisition of communicative competence: possible parallels between avian and human learning. In: Zentall TR, Galef BG, editors. Social learning: a comparative approach. Hillsdale, NJ: Erlbaum. p 279-299.

Pepperberg IM, Brese KJ, Harris BJ. 1991. Solitary sound play during acquisition of English vocalizations by an African gray parrot (Psittacus erithacus): possible parallels with children's monologue speech. Appl Psychol 12:151-178.

Plummer TK, Striedter GF. 1997. Auditory and vocalization related activity in the vocal control system of budgerigars. Soc Neurosci Abstr 100:10.

Pospelov VA, Pospelova TV, Julien J-P. 1994. AP-1 and Krox-24 transcription factors activate the neurofilament light gene promoter in P19 embryonal carcinoma cells. Cell Growth Differ 5:187-196.

Puelles L, Robles C, Martinez-de la Torre T, Martinez S. 1994. New subdivisions schema for the avian torus semicircular: neurochemical maps in the chick. J Comp Neurol 340:98-152.

Reinke H, Wild JM. 1998. Identification and connections of inspiratory premotor neurons in songbirds and budgerigar. J Comp Neurol 391: 147-163.

Reiss D, McCowan B. 1993. Spontaneous vocal mimicry by bottlenose dolphins (Tursiops truncatus): evidence for vocal learning. J Comp Psychol 107:301-312.

Ribeiro S, Cecchi GA, Magnasco MO, Mello C. 1998. Toward a song code: evidence for a syllabic representation in the canary brain. Neuron 21:359-371

Scharff C, Nottebohm F. 1991. A comparative study of the behavioral deficits following lesions of various parts of the zebra finch song system: implications for vocal learning. J Neurosci 11:2896-2913.

Schimdt MF, Konishi M. 1998. Gating of auditory responses in the vocal control system of awake songbirds. Nature Neurosci 1:513-518.

Sheng M, Greenberg M. 1990. The regulation and function of c-fos and other immediate early genes in the nervous system. Neuron 4:477-485.

Sibley CG, Ahlquist JE. 1990. The phylogeny and classification of birds. New Haven, CT: Yale University Press.

Sohrabji F, Nordeen EJ, Nordeen KW. 1990. Selective impairment of song learning following lesions of a forebrain nucleus in the juvenile zebra finch. Behav Neural Biol 53:51-63.

Striedter GF. 1994. The vocal control pathways in budgerigars differ from those in songbirds. J Comp Neurol 343:35-56.

Striedter GF. 1997. The telencephalon of tetrapods in evolution. Brain Behav Evol 49:179-213.

Striedter GF, Yu ET. 1998. Bilateral feedback projections to the forebrain in the premotor network for singing in zebra finches. J Neurobiol 34: $27-40$.

Stripling R, Volman S, Clayton D. 1997. Response modulation in the zebra finch caudal neostriatum: relationship to nuclear gene regulation. J Neurosci 17:3883-3893.

Thiel G, Schoch S, Petersohn D. 1994. Regulation of synapsin I gene expression by the zinc finger transcription factor zif268/egr-1. J Biol Chem 269:15294-15301.

Thorpe WH. 1961. Bird song. Cambridge: Cambridge University Press.

Vates GE, Nottebohm F. 1995. Feedback circuitry within a song learning pathway. Proc Natl Acad Sci USA 92:5139-5143.

Vates GE, Broome BM, Mello CV, Nottebohm F. 1996. Auditory pathways of caudal telencephalon and their relation to the song system of adult male zebra finches (Taenopygia guttata). J Comp Neurol 366:613-642.

Vates GE, Vicario DS, Nottebohm F. 1997. Reafferent thalamo-"cortical" loops in the song system of oscine songbirds. J Comp Neural 380:275290.

Veenman CL, Wild JM, Reiner A. 1995. Organization of the avian "corticostriatal" projection system: a retrograde and anterograde pathway tracing study in pigeons. J Comp Neurol 354:87-126.

Veenman CL, Medina L, Reiner A. 1997. Avian homologues of mammalian intralaminar, mediodorsal and midline nuclei: immunohistochemical and hodological evidence. Brain Behav Evol 49:78-98.

Vicario DS. 1993. A new brain stem pathway for vocal control in the zebra finch song system. Neuroreport 4:983-986.

Wild JM. 1993. Descending projection of the songbird nucleus robustus archistriatalis. J Comp Neurol 338:225-241.

Wild JM. 1994. The auditory-vocal-respiratory axis in birds. Brain Behav Evol 44:192-209.

Wild JM. 1997. Neural pathways for the control of birdsong production. Neurobiology 33:653-670.

Wild JM, Arends JJA, Zeigler HP. 1990. Projections of the parabrachial nucleus in the pigeon (Columbia livia). J Comp Neurol 293:499-523.

Wild JM, Karten HJ, Frost BJ. 1993. Connections of the auditory forebrain in the pigeon (Columbia livia). J Comp Neurol 337:32-62.

Wild JM, Reinke H, Farabaugh SM. 1997a. A nonthalamic pathway contributes to a whole body map in the brain of the budgerigar. Brain Res 755:137-141.

Wild JM, Li D, Eagleton C. 1997b. Projections of the dorsomedial nucleus of the intercollicular complex (DM) in relation to respiratory-vocal nuclei in the brainstem of pigeon (Columbia livia) and zebra finch (Taeniopygia guttata). J Comp Neurol 377:392-413.

Wiley H. 1971. Song groups in a singing assembly of little hermits. Condor $73: 28-35$. 